\title{
Externalidades Positivas ou Efeitos Excludentes? Integração Socioeconômica de Três Bairros Populares em Salvador em relação aos seus Condomínios Vizinhos de Elite ${ }^{1}$
}

\author{
Stephan Treuke ${ }^{1}$ \\ ${ }^{1}$ Doutor em Ciências Socias pela Universidade Federal da Bahia (UFBA). Salvador, BA. \\ E-mail: stephantreuke@hotmail.de.

\section{INTRODUÇÃO}

D esde o final da década de 1980, a Sociologia Urbana estadunidense vem investigando as relações entre a segregação residencial racial e a reprodução da pobreza à luz do conceito de efeito-territórioº (Small e Feldman, 2012). O debate em torno da concentração espacial da pobreza (Wilson, 1987) tem impulsionado a implementação de políticas de dessegregação que visam ampliar as oportunidades de integração socioeconômica de famílias afro-americanas e pobres através do seu deslocamento da inner city ${ }^{3}$ fortemente segregada para bairros suburbanos da classe média (Ludwig et al., 2008).

Essas políticas se baseiam na assunção de que a proximidade geográfica das famílias pobres a grupos sociais de maior status socioeconômico: (1) estimula as articulações interclasse; (2) favorece o acesso a informações sobre vagas de emprego; (3) fortalece o controle social informal da comunidade; (4) amplia a exposição a modelos de referência social da classe média; e (5) proporciona um melhor acesso a serviços urbanos de alta qualidade (Galster e Killen, 1995; Joseph e Chaskin, 2010). A mesma premissa de "externalidades positivas" criou a base para a elaboração de políticas de social mixing implementadas em cidades estadunidenses e europeias (Galster, 2007). 
Em diferença ao antagonismo inner city vs. subúrbio/região metropolitana, inerente à organização socioespacial das metrópoles estadunidenses, as cidades latinoamericanas sempre abrigaram tanto padrões de segregação macrossocial do tipo centro-periferia quanto configurações espaciais marcadas pela proximidade espacial entre grupos socialmente distantes ${ }^{4}$ (Borsdorf et al., 2015; Sabatini, 2003). Esta última configuração socioespacial - que se reproduziu nas porções centrais e no vetor de expansão das classes média e alta - não pode ser considerada como resultado produzido por políticas habitacionais, senão como dinâmica intrínseca à expansão territorial das metrópoles latinoamericanas (Borsdorf et al., 2002).

Sustenta-se que essa relação de proximidade continua proporcionando uma série de vantagens para a integração socioeconômica das populações pobres habitando as porções centrais das cidades (Kaztman, 1999; Kowarick, 2009). Entretanto, estudos conduzidos em bairros pobres localizados dentro do vetor de expansão das classes média e alta apontam a diminuição das articulações (não)empregatícias entre os grupos socialmente distantes, em função do acesso segmentado aos serviços urbanos, do declínio da função de integração social do espaço público e da maior ocorrência de crimes vinculados ao tráfico de drogas (Bayon e Saravi, 2013; Kaztman e Retamoso, 2006).

Recentemente, a análise da relação entre proximidade espacial e integração socioeconômica vem sendo retomada através de pesquisas que examinam o impacto espacial e social da construção de condomínios da elite nas regiões periféricas das grandes cidades, predominantemente habitadas por uma população de baixa renda (Janoschka e Sequera, 2016; Ruiz-Tagle, 2016; Sabatini e Salcedo, 2007). A maioria dos autores adere ao argumento que a autossegregação das camadas média e alta reproduz a segregação residencial e a segmentação social na escala microurbana (Caldeira, 2000; Parnreiter, 2004; Ruiz-Tagle, 2016). Esse desdobramento favoreceria as articulações intraclasse dentro dos condomínios fechados, contribuiria à redução das relações não empregatícias entre grupos socialmente distantes e promoveria a retração das camadas média e alta da esfera pública (Caldeira, 2000; Janoschka e Borsdorf, 2004; Svampa, 2001), conforme já observado no contexto estadunidense (Low, 2000).

Contudo, uma série de estudos qualitativos tem comprovado que a proximidade aos condomínios da classe média e alta pode estimular as articulações funcionais (acesso a oportunidades empregatícias), sociais 
(trocas de sociabilidade) e simbólicas (revalorização da imagem do bairro pobre) entre os grupos socialmente distantes, fato que mitiga o efeito da segregação nas regiões periféricas de Santiago de Chile (Sabatini e Salcedo, 2007; Salcedo e Torres, 2004). Entretanto, o Brasil carece de estudos qualitativos que examinam o impacto da construção de condomínios fechados na transformação social e espacial das regiões periféricas das grandes cidades.

Atentando a esse desideratum, este estudo busca investigar sob quais condições a proximidade a bairros de elite mitiga o impacto do efeito-território em três bairros populares de Salvador, Brasil. À base de 60 entrevistas semiestruturadas, comparam-se as oportunidades de integração socioeconômica da população do bairro Calabar, localizado próximo à região central da cidade, com o Bate Facho, bairro inserido no vetor de expansão das classes média e alta, e com o bairro Vila Verde, localizado nas imediações do recém-construído condomínio de elite Alphaville 2. A integração do bairro Vila Verde nos permite analisar in statu nascendi a emergência de uma nova configuração de proximidade entre grupos socialmente distantes e se torna particularmente relevante para os estudos urbanos contemporâneos, considerando-se que são crescentemente as regiões periféricas das grandes cidades latinoamericanas que se tornam alvo de grandes empreendimentos imobiliários da elite (Borsdorf e Hidalgo; Vidal-Koppmann, 2015; Ruiz-Tagle, 2016).

O artigo está composto por quatro seções, excetuando-se a introdução e as considerações finais. A primeira seção aborda os principais desenvolvimentos teóricos dentro da discussão acerca do conceito de efeito-território. A segunda seção introduz a metodologia utilizada no estudo empírico. Já a terceira expõe os resultados obtidos na pesquisa qualitativa, enquanto a quarta seção discute os principais achados empíricos à luz do referencial teórico deste estudo.

\section{A ABORDAGEM DO EFEITO-TERRITÓRIO NOS ESTUDOS URBANOS}

A discussão em torno do efeito-território foi instigada a partir da abordagem estruturalista da pobreza urbana por Wilson (1987). Sua argumentação se norteia no conceito de isolamento social, definido como a dissociação do indivíduo pobre vis-à-vis pessoas e instituições representando a sociedade dominante. $\mathrm{O}$ seu confinamento ao contexto social local também dificultaria sua integração econômica em função da falta de acesso a informações sobre vagas de emprego 
(Small e Feldman, 2012). Wilson (1987) assevera que a saída da classe média afro-americana da inner city teria enfraquecido a capacidade de integração social vertical da população local, considerando-se seu papel de assegurar a viabilidade econômica da infraestrutura social e comercial e de transmitir valores e referências sociais positivas. Posteriormente, Sampson (2012) demonstrou que o efeito-território se vê atenuado pela capacidade de controle social informal na escala da comunidade. Vice-versa, a erosão da collective efficacy ${ }^{5}$ favoreceria a infiltração de estruturas criminosas na sua organização social.

O debate em torno do efeito-território e do enfraquecimento da organização socioinstitucional dos guetos da inner city impulsionou a implementação de políticas de dessegregação nas metrópoles estadunidenses, que podem ser classificadas como people based policies (Sampson, 2012), já que são centradas na família como unidade de intervenção. Contrariando as expectativas, não se evidenciaram melhorias substanciais na estrutura de oportunidades das famílias relocadas, no que tange as áreas de educação e emprego (Ludwig et al., 2008).

Posteriormente, essas estratégias de dispersão espacial da pobreza foram complementadas por políticas de social mixing. Todavia, estudos avaliando o impacto dessas políticas comprovam que esse modelo de habitação não beneficia a integração socioeconômica das camadas baixas, já que a escassez de articulações extrapolando a própria classe social impede o acesso a informações sobre vagas de emprego e a exposição a modelos de referência positivos (Joseph e Chaskin, 2010).

Uma série de pesquisas tem comprovado que a proximidade a vizinhos de maior status econômico pode aumentar os sentimentos de privação relativa do indivíduo pobre (Kearns e Mason, 2007) e aumentar as tensões intergrupais, dada a maior visibilidade das clivagens socioeconômicas e o acesso segmentado ao sistema de educação, transporte e lazer (Clampet-Lundquist e Massey, 2007).

Small (2004) demonstra que os habitantes pobres da Villa Victoria, um enclave étnico localizado em proximidade ao bairro de elite de South-End, em Boston (EUA), mantém poucos contatos sociais com seus vizinhos, dada sua estigmatização territorial e em razão do acesso segmentado aos serviços urbanos. Outrossim, o autor argumenta que a disposição da infraestrutura comercial, social e cultural em Villa Victoria favorece o isolamento social da população local em decorrência da 
falta de necessidade de acessar recursos (não) materiais fora do bairro, excetuando-se o lugar de trabalho. Essas importantes considerações serão retomadas na construção dos conceitos metodológicos "grau de autonomia funcional do bairro" $\mathrm{e}$ "grau de imbricação funcional", de grande relevância para a análise do efeito-território neste estudo. Existe um crescente consenso de que as políticas de social mixing não contribuem à integração socioeconômica das camadas baixas, a não ser que sejam flanqueadas por investimentos locais em serviços sociais, educação, transporte público e programas de capacitação profissional (Wilson, 1987). Essas políticas podem ser classificadas como place based policies, já que visam ampliar as oportunidades de integração socioeconômica do indivíduo na escala do bairro (Sampson, 2012).

Entretanto, a abordagem da pobreza na Europa se norteia no conceito de exclusão social que assinala o distanciamento do indivíduo do estado de integração plena na sociedade, considerando-se aspectos econômicos, político-institucionais, sociais e culturais (Wacquant, 2016). Diversos estudos sinalizam um impacto menos significativo do efeito-território nas condições de vida do indivíduo, principalmente em razão de um modelo de planejamento urbano socialmente mais integrativo e de um sistema de bem-estar social considerado mais robusto (Friedrichs et al., 2003). Contudo, o aumento das disparidades de renda e a crescente polarização socioespacial das grandes cidades instigaram um debate mais amplo sobre o efeito negativo da concentração espacial de desvantagens estruturais nas condições de vida do indivíduo pobre (Galster, 2007).

Similar ao contexto estadunidense, os governos municipais têm recorrido a estratégias de social mixing para evitar processos de segregação residencial de determinados grupos sociais ou étnico-raciais (Musterd et al., 2015). Todavia, pesquisas investigando a situação de "convivência" entre grupos socialmente distantes revelam que a proximidade espacial não promove automaticamente uma maior integração socioeconômica das camadas baixas (Blanc, 2010; Chamboredon e Lemaire, 1970). Já Bourdieu (1979) frisava que a proximidade geográfica entre os grupos socialmente distantes não elimina as relações de dominação: as trocas de sociabilidades entre os grupos socialmente distantes não se produzem em virtude da manutenção das hierarquias reificadas pela assimétrica disposição de capital econômico, social e simbólico que define a atuação da classe média e alta em relação às camadas mais baixas. 
Pesquisas mais contemporâneas avaliando o efeito das políticas de social mixing destacam a prevalência de interações sociais entre pessoas pertencendo à mesma classe e a falta de percepções compartilhadas sobre a coesão e solidariedade intracomunitária, devido ao uso diferenciado dos espaços de lazer, do sistema educativo e do transporte público/privado (Butler; Robson, 2003; Davidson, 2010). A maioria dos autores pleiteia por uma intervenção mais regulatória do Estado no mercado laboral e habitacional e pela implementação de políticas setoriais, capazes de promover uma maior equidade no acesso às oportunidades de integração socioeconômica (Galster, 2007). Essa aproximação às desigualdades sociais pode ser denominada de indirect approach (Sampson, 2012).

Na América Latina, prevalece uma abordagem da pobreza urbana que ora analisa suas causas e consequências através de um enfoque estruturalista (Kaztman, 1999), ora examina as estratégias de sobrevivência desenvolvidas pelas famílias pobres para mitigar sua situação de vulnerabilidade social (Kowarick, 2009; Moser, 1998; Perlman, 2010). Entretanto, o contexto sociorresidencial do bairro, enquanto fator reprodutor da pobreza, não se constituiu em categoria analítica autônoma, apesar da historicamente forte concentração espacial de desvantagens estruturais, nomeadamente nos bairros periféricos das grandes metrópoles (Roberts e Wilson, 2009).

Contudo, recentemente, cristaliza-se um crescente interesse em examinar as causalidades entre a segregação residencial econômica e a reprodução da pobreza na escala do bairro. Estudos quantitativos corroboram o impacto do efeito-território no nível de renda, no acesso ao mercado de trabalho e na modalidade formal/informal do emprego desempenhado, que prejudica as populações pobres vivendo em bairros periféricos (Roberts e Wilson, 2009). Essas dificuldades decorrem da distância geográfica aos principais mercados de trabalho formal que se concentram no centro da cidade assim como das práticas de discriminação na busca de emprego (Kowarick, 2009). Ribeiro et al. (2010) destacam que a falta de investimentos públicos em instituições de educação nesses locais se traduz em uma maior distorção idade-série, em um baixo desempenho escolar e em um frequente abandono da escola.

Outrossim, Kaztman (1999) aponta a ausência de modelos de referência valorizando a educação como caminho formal para a integração econômica, fato que estimula a adesão a modelos criminosos de provisão 
de renda. $\mathrm{O}$ autor assevera que nos bairros segregados da periferia de Montevideu, Uruguai, existem poucos contatos com pessoas e instituições da classe média, situação que prejudica seu acesso a informações sobre empregos. Enquanto estas considerações corroboram em grandes linhas a hipótese do isolamento social postulado por Wilson (1987), Marques (2010), observa que, em diferentes bairros pobres e periféricos de São Paulo, o efeito da segregação pode tornar a sociabilidade do indivíduo mais dispersa e diversificada, dado o imperativo de acessar recursos extralocais. Entretanto, o autor destaca a escassez de articulações extrapolando a própria classe social, ressalvando, no entanto, que tal situação não dificulta necessariamente a integração do indivíduo pobre no mercado laboral formal.

Observa-se um maior dissenso referente à questão de quanto a proximidade a bairros da classe média e alta amplia as oportunidades de integração socioeconômica dos indivíduos pobres. Na América Latina essa configuração socioespacial se reproduziu tanto nas regiões centrais quanto dentro do vetor de expansão da classe média e a alta, em razão: (1) da convivência física entre os grupos socialmente distantes já no período colonial; (2) do relativo laissez-faire do Estado com respeito à invasão de terras públicas desocupadas pelas camadas baixas; (3) da resistência das populações contra as políticas de remoção dos slums; e (4) das políticas de zoneamento implementadas com o objetivo de proteger seus habitantes contra a especulação fundiária.

Um primeiro grupo de pesquisadores, enfocando essas configurações socioespaciais nas regiões centrais das grandes cidades, destaca as vantagens locacionais beneficiando a integração empregatícia da população pobre (Kaztman, 1999; Kowarick, 2009). Kaztman e Wormald (2002) argumentam que nesses lugares existia uma maior chance de interação entre os grupos socialmente distantes a partir do uso compartilhado dos serviços urbanos locais.

Um segundo grupo de pesquisadores, enfocando configurações socioespaciais similares que emergiram ao longo do processo de expansão das classes média e alta, assinala o enfraquecimento da capacidade de transmissão de modelos de referências da classe média e o declínio das articulações não empregatícias entre os grupos socialmente distantes, dada a crescente bifurcação entre um sistema público e privado de serviços urbanos (Bayón e Saraví, 2013; Kaztman e Retamoso, 2008). Essa dinâmica foi acompanhada pela privatização do espaço público e do 
maior isolamento espacial das camadas média e alta em condomínios fechados fortemente protegidos (Caldeira, 2000). As clivagens socioeconômicas inscritas no espaço se traduzem em maiores conflitos e tensões entre os moradores dos condomínios de elite e sua circunferência pobre, considerando-se que essas regiões também apresentam níveis de violência mais elevados, particularmente no contexto urbano brasileiro.

No entanto, prevalecem as amplas oportunidades de integração econômica, principalmente no setor da construção civil e nos serviços pessoais desempenhados nos condomínios (Andrade e Silveira, 2013). Para Almeida e d'Andrea (2004), além de providenciar oportunidades empregatícias, os moradores do bairro de elite do Morumbi, em São Paulo, participam em associações filantrópico-assistencialistas que objetivam combater a pobreza e a violência na favela vizinha, Paraisópolis. Gledhill e Hita (2018) chegam a conclusões similares à base da exploração das distintas formas de interação entre os moradores do bairro popular Bairro da Paz, em Salvador, e dos condomínios de elite circunferentes.

Um terceiro grupo de pesquisadores vem examinando a relação entre proximidade espacial e integração socioeconômica nas regiões periféricas que recentemente viram sua organização socioespacial transformada pela construção de condomínios fechados (Ruiz-Tagle, 2016). Esses desdobramentos espaciais são abordados no contexto latinoamericano a partir do conceito de gentrificação, destacando-se três eixos temáticos:

1. a discussão sobre o impacto do deslocamento das camadas média e alta para as regiões centrais da cidade. Essas regiões, habitadas predominantemente pelas camadas baixas, também se tornam objeto de programas de revitalização urbana visando promover o turismo global. Ambos os desdobramentos são examinados à luz da tendência de privatização do espaço urbano que, em conjunção com um forte policiamento, cria obstáculos à apropriação das praças públicas pelo subproletariado para a venda informal de diversos produtos;

2. o debate centrado na implementação de programas de reestruturação urbana financiados por empresas imobiliárias nacionais ou estrangeiras que exploraram o diferencial de renda - principalmente nas porções centrais da cidade; 
3. a análise do impacto das políticas de pacificação implementadas em diferentes bairros pobres localizados em regiões altamente valorizadas. Em conjunção com investimentos públicos em serviços urbanos locais e as políticas de regularização do título de posse de moradia, acarretam o aumento das despesas para a população local, assim contribuindo para seu deslocamento a regiões mais periféricas (Janoschka e Sequera, 2016).

No Brasil, a abordagem da gentrificação apenas recentemente se constituiu em vertente temática independente dentro dos estudos urbanos. As pesquisas se debruçam majoritariamente na análise do impacto de distintos programas de revitalização urbana implementados nas regiões mais valorizadas das cidades (Gledhill e Hita, 2018). Entretanto, carece de estudos examinando o impacto da construção de condomínios fechados de elite na transformação social e espacial das regiões periféricas das grandes cidades. Convém ressaltar que, no Brasil, esses condomínios fechados recentemente construídos se constituíram em bairros autônomos; amiúde, são separados por muros, pelo ambiente construído ou por barreiras naturais, conforme também pode ser observado em outras cidades latinoamericanas (Janoschka e Borsdorf, 2004; Janoschka et al., 2014).

Já no contexto chileno, os condomínios fechados da classe alta se inserem literalmente no meio dos bairros pobres e periféricos de Santiago - situação que abre maiores possibilidades de comparação com o contexto de social mixing nas cidades estadunidenses. Sabatini e Salcedo (2007) e Salcedo e Torres (2004), examinando as consequências socioespaciais da construção de condomínios fechados de elite nos bairros periféricos de Santiago do Chile, concordam em enfatizar os benefícios para a integração empregatícia da população pobre que decorrem da demanda dos moradores dos condomínios em serviços pessoais, como jardineiro, porteiro, faxineira, etc., mas também assinalam outras "externalidades positivas", como a valorização do bairro na sua percepção subjetiva.

Entretanto, os estudos conduzidos por Ruiz-Tagle (2016) no bairro periférico de La Florida, na cidade de Santiago, evidenciam que as chances de se ser contratado como funcionário dentro dos condomínios de elite são prejudicadas pela estigmatização da população moradora daquele bairro, ao mesmo tempo que se mantém inalterado o acesso segmentado aos serviços urbanos de alta qualidade. $O$ autor sustenta que a dimensão espacial representa apenas uma variável interveniente dentro da concepção de 
"integração social", ao lado das demais dimensões "funcional" (acesso a empregos e serviços urbanos), "relacional" (interações não empregatícias entre grupos socialmente distantes) e "simbólica" (identificação territorial). Essas observações se alinham à aproximação multidimensional e às desigualdades sociais, conforme proposto pela teoria de campos de Bourdieu (1979), e possuem importantes implicações para as políticas de social mixing que, no contexto chileno, partem de uma relação virtuosa $a$ priori entre proximidade espacial e integração socioeconômica.

No Brasil, entretanto, as políticas de habitação social, desenhadas com o objetivo de promover um espaço de moradia acessível para as populações de baixa renda nas regiões altamente valorizadas das grandes cidades, enfrentam uma forte resistência do setor imobiliário (Klink e Denaldi, 2015). Na sua grande maioria, elas foram implementadas nas regiões (semi) periféricas que continuam acumulando uma série de deficiências em termos de acesso a serviços urbanos (Santoro, 2015).

Sintetizando, convém destacar que a abordagem do efeito-território na Sociologia Urbana Brasileira se assenta em avaliações quantitativas, enfatizando-se seu impacto na mobilidade socioeconômica do indivíduo. Em vez de focalizar em uma variável específica, parte-se, neste trabalho, da multidimensionalidade do efeito-território, em consonância com os postulados de Bourdieu (1979). Seguindo as considerações de Häußermann (2003), pressupõe-se que o contexto sociorresidencial não interfere apenas no acesso ao mercado de trabalho e desempenho escolar, senão que afeta também os padrões de sociabilidade e a percepção subjetiva do indivíduo.

\section{CONSIDERAÇÕES METODOLÓGICAS E ÁREAS DE ESTUDO}

Para o propósito desta pesquisa, convém examinar, em primeiro lugar, o impacto do efeito-território nas condições de vida dos moradores dos três locais para, em segundo lugar, analisar as articulações (não) empregatícias entre os grupos socialmente distantes à luz do seu potencial de mitigar tal efeito.

Nesse sentido, recorre-se à aproximação metodológica ao efeito-território proposta por Häußermann (2003) que distingue entre três dimensões analíticas estreitamente interligadas, quais sejam: (1) a dimensão material; (2) a dimensão social; e (3) a dimensão simbólica. Na dimensão material, abordam-se aspectos atinentes às oportunidades empregatícias locais, ao acesso a serviços urbanos e à infraestrutura comercial, social e 
cultural no bairro. Já na dimensão social, examinam-se a estrutura das redes sociais e a influência de grupos de pares em processos de socialização. Acrescenta-se a essa dimensão a análise da capacidade de collective efficacy (Sampson, 2012), já que se pressupõe um impacto significativo do crime na organização social da comunidade e nas condições de vida dos seus moradores. Por fim, na dimensão simbólica, investiga-se o impacto da estigmatização territorial no acesso ao mercado de trabalho e nos padrões de sociabilidade do indivíduo.

Para examinar as articulações não empregatícias entre os grupos socialmente distantes, recorre-se às considerações de Hannerz (1980) sobre as distintas funções que o bairro de residência desempenha na reprodução social do indivíduo, quais sejam: a família; a provisão de recursos materiais, sociais e culturais; o lazer; a vizinhança; o transporte. A distribuição dessas funções - analisada neste trabalho a partir da variável "grau de autonomia funcional do bairro" - incide sobre o grau de abertura ou de isolamento social que o local de residência promove nas articulações cotidianas do indivíduo. Pressupõe-se uma variabilidade entre, por um lado, o preenchimento de todas as supracitadas funções no bairro e, por outro, a ausência dessas funções - abstraindo-se dos fatores "família" e "vizinhança", que possuem um caráter essencialmente local. Já o "grau de imbricação funcional" da população vis-à-vis os bairros circunferentes de elite leva em consideração as articulações econômicas (relações empregatícias), sociais (trocas de sociabilidade) e simbólicas (percepção do "outro") entre os grupos socialmente distantes. Pressupõe-se que este "grau de imbricação funcional" diminui em configurações de vizinhança onde inexistem espaços públicos compartilhados e onde dispositivos de segurança dificultam as trocas de sociabilidade e a mercantilização de produtos.

O estudo foi conduzido em três bairros populares: Calabar, Bate Facho e Vila Verde, localizados dentro do município de Salvador, a quarta maior cidade do Brasil, com aproximadamente 2,7 milhões de habitantes. A Figura 1 aponta uma nítida divisão do município em quatro macrorregiões, seguindo-se critérios essencialmente socioeconômicos: o Centro e a Orla Atlântica - abrigando as classes média e alta e concentrando a maioria dos postos de emprego e dos serviços urbanos de alta qualidade -, o Subúrbio Ferroviário/Ilhas, onde predomina uma população majoritariamente de baixa renda, e o "Miolo Urbano", habitado pela classe (média) baixa. A Figura 1 também retrata os distintos vetores de expansão territorial das camadas média e alta no 
município de Salvador, sendo que a primeira fase (1940-1960) corresponde ao deslocamento desses grupos sociais do centro histórico para as regiões litorâneas mais próximas da Orla Atlântica; a segunda fase (1960-2000), à ocupação do espaço intersticial entre a Avenida Paralela e a Avenida Otávio Mangabeira / Avenida Oceânica; e a terceira fase (2000 até atual), à construção de condomínios fechados de elite em ambos lados da Avenida Paralela.

Figura 1

Vetores de Expansão das Camadas Média e Alta no Município de Salvador

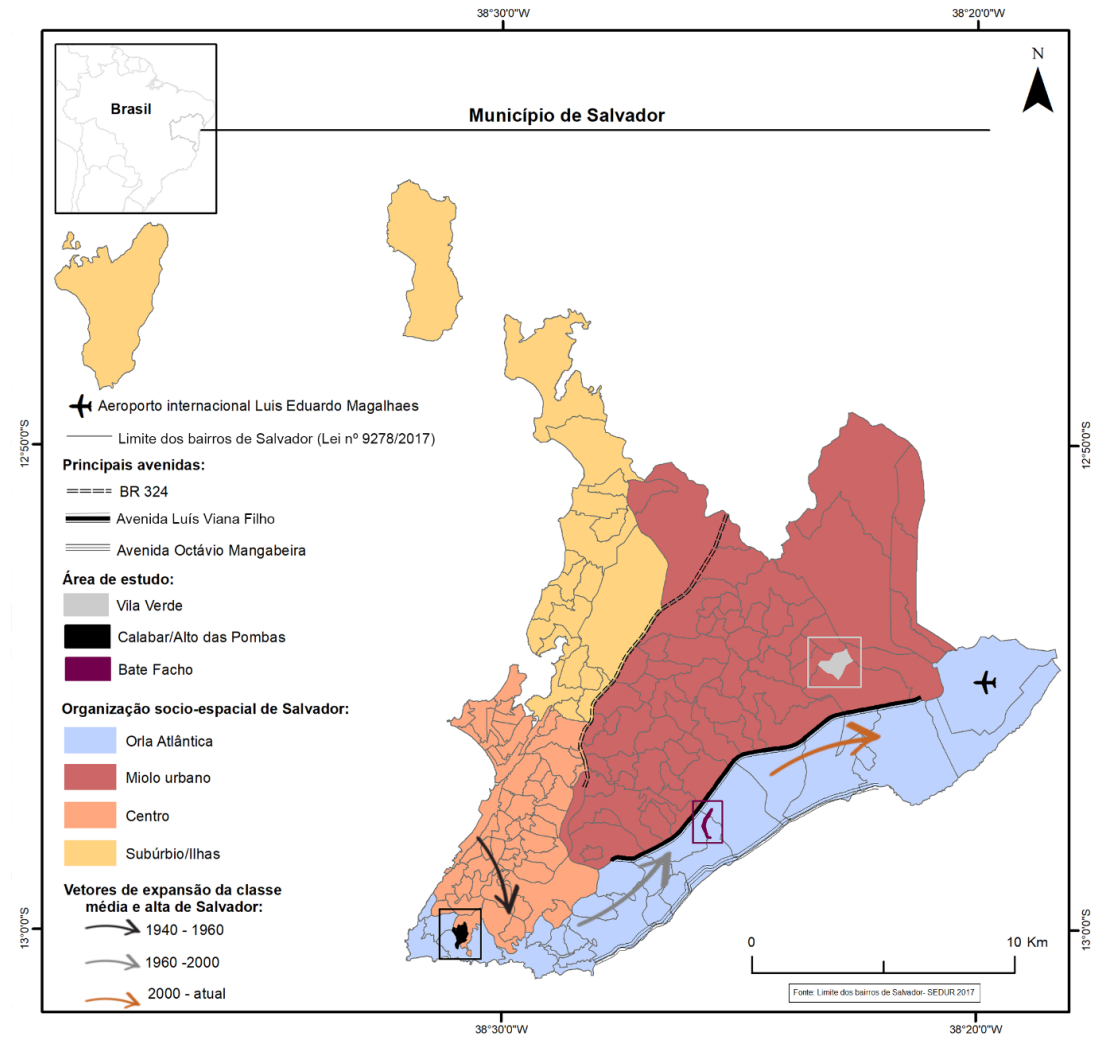

Fonte: Elaboração própria, com base em SEDUR (2017).

As Figuras 2 e $3^{6}$ retratam as fortes disparidades com respeito ao nível médio de renda familiar e nível de escolaridade do chefe de família que se manifestam, na escala macrourbana, no antagonismo entre centro (Centro e Orla Atlântica) e periferia (Subúrbio Ferroviário/Ilhas e "Miolo Urbano"). Já na escala microurbana, o município se caracteriza por uma organização socioespacial mais fragmentada, caracterizada 
pela proximidade geográfica entre bairros abrigando uma população de alto status socioeconômico e bairros populares, onde predomina uma população de baixos níveis de renda e escolaridade.

\section{Figura 2}

Distribuição dos Grupos Sociais a partir do Critério de Renda em Salvador

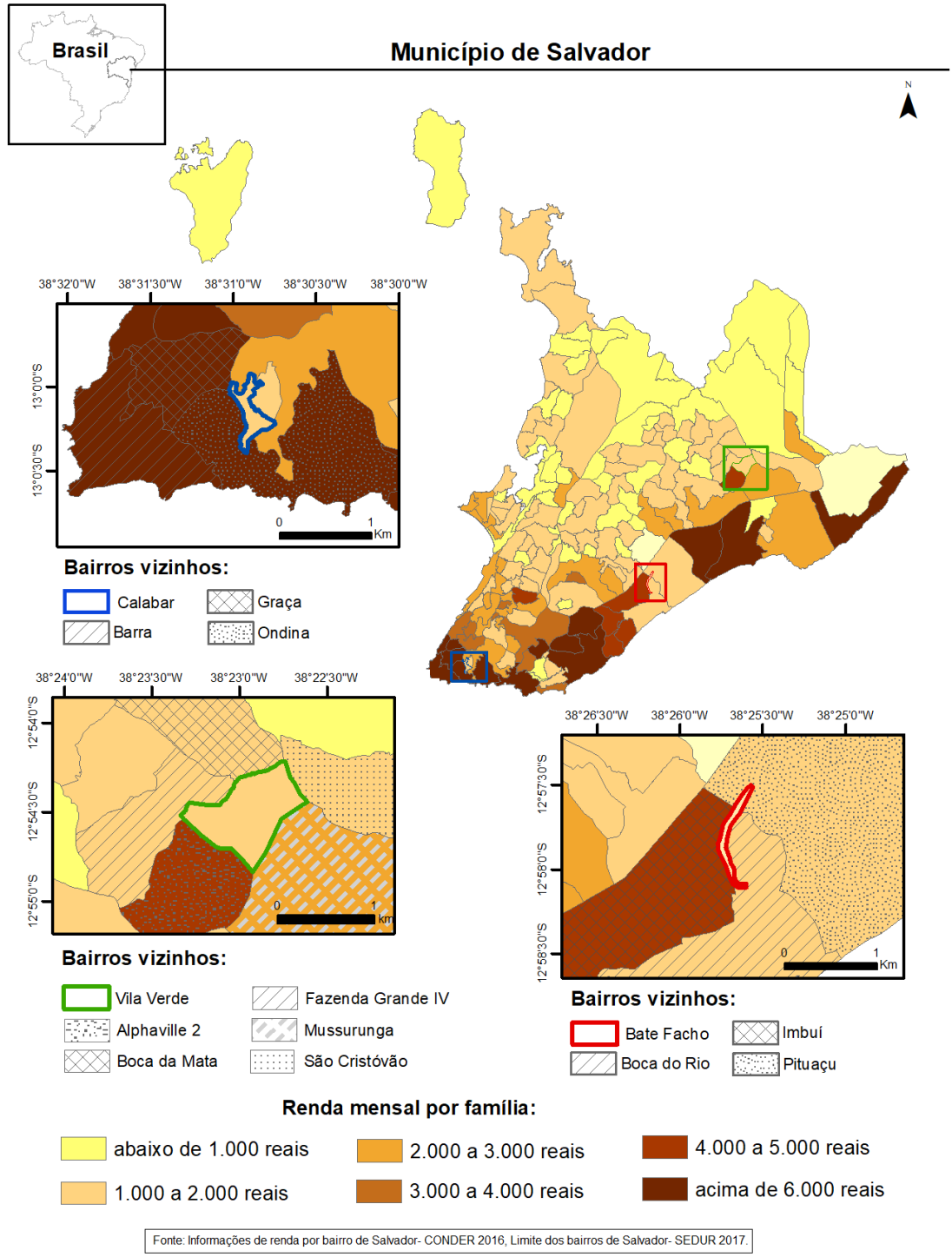

Fonte: Elaboração própria, com base em CONDER (2016) e SEDUR (2017). 
Figura 3

Distribuição dos Grupos Sociais a partir da Proporção de Chefes de Família com Nível de Educação Superior em Salvador

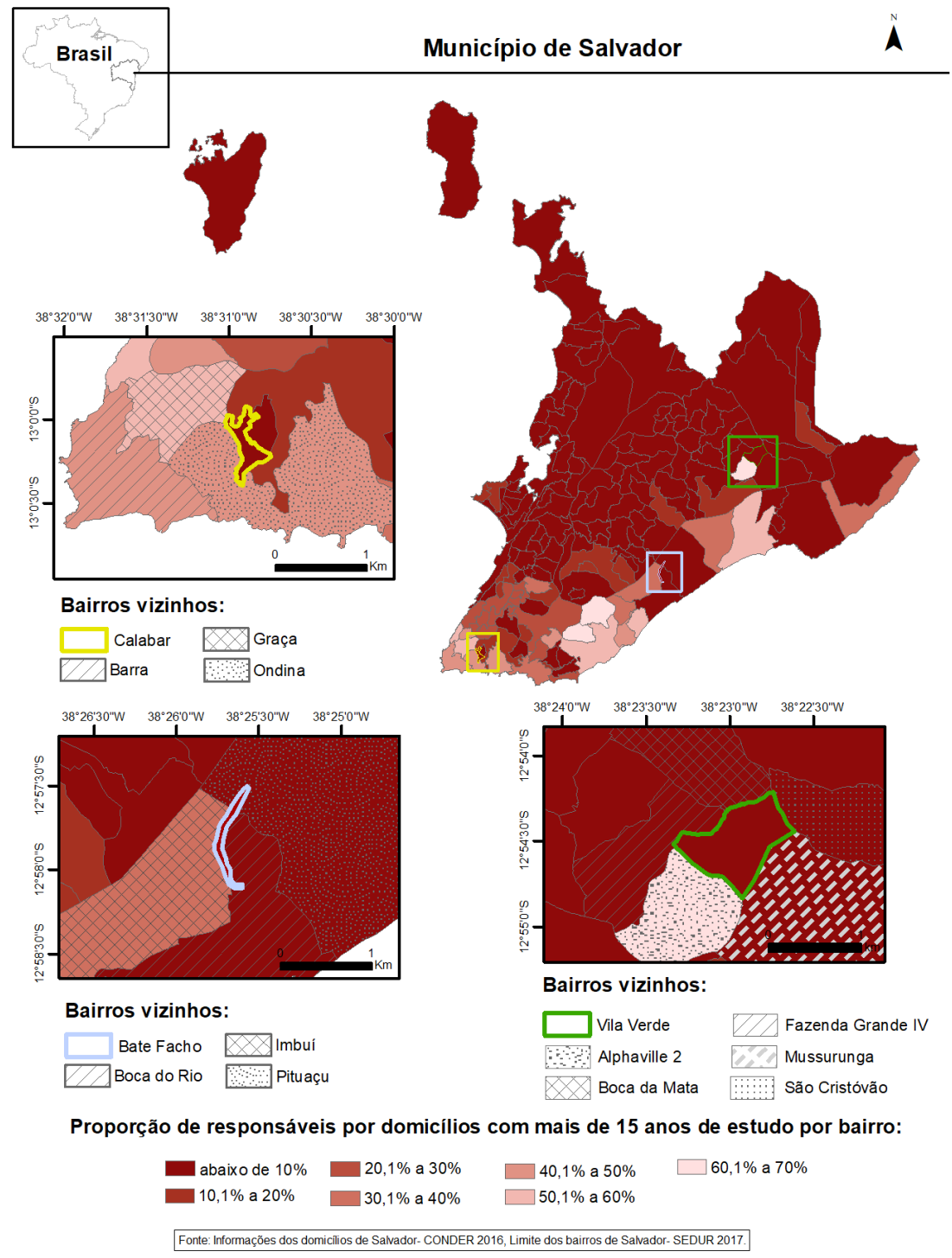

Fonte: Elaboração própria, com base em CONDER (2016) e SEDUR (2017). 
O antagonismo entre centro e periferia, com respeito ao nível de renda e escolaridade, coaduna com uma maior concentração espacial de homicídios no subúrbio Ferroviário/Ilhas e no "Miolo Urbano", enquanto o Centro e a Orla Atlântica apresentam um número menor de ocorrências, conforme ilustrado pela Figura 4.

Figura 4

Distribuição da Quantidade de Homicídios Registrados por AISPs em Salvador

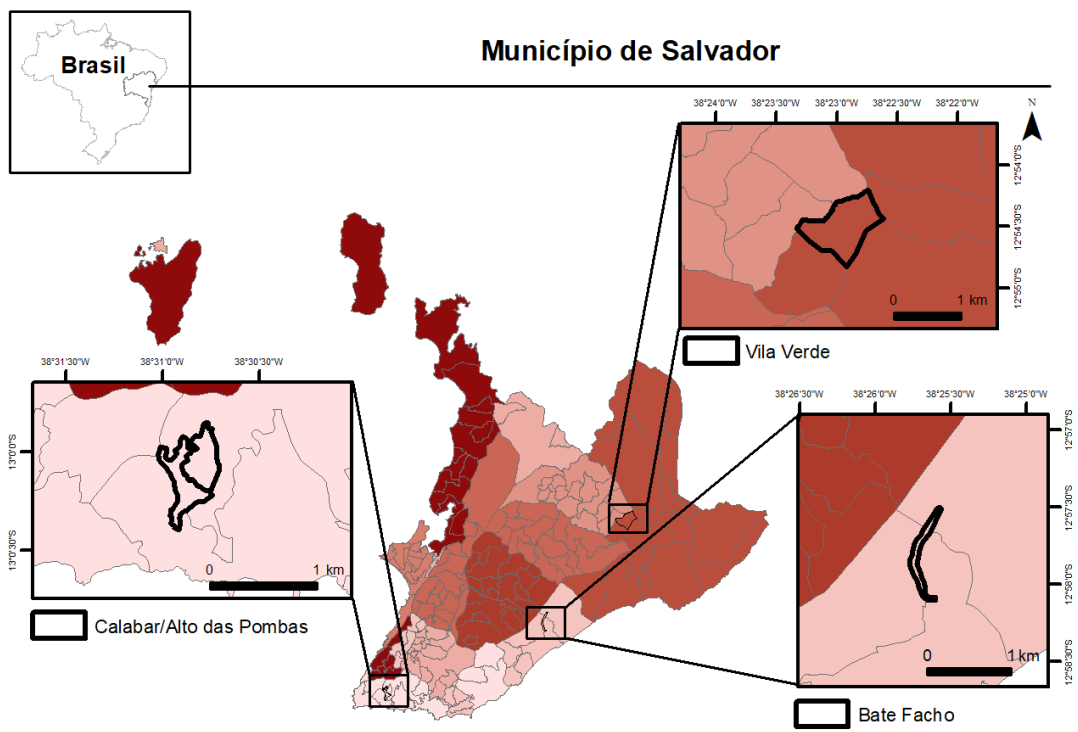

Distribuição espacial dos homicídios por Áreas Integradas de Segurança Pública

\begin{tabular}{|c|c|c|c|}
\hline $2-15$ & $31-45$ & $61-75$ & $91-105$ \\
\hline $16-30$ & $46-60$ & $76-90$ & $106-120$ \\
\hline
\end{tabular}

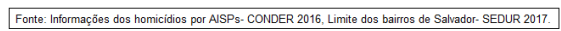

Fonte: Elaboração própria, com base em CONIDER (2016) e SEDUR (2017)

Essa distribuição desigual dos homicídios pelo município de Salvador se torna relevante para a interpretação dos resultados, considerando-se que o bairro Vila Verde se insere em uma região periférica apresentando altos níveis de homicídios. Os bairros que servem de recorte empírico representam de forma paradigmática três distintas configurações espaciais marcadas pela proximidade entre grupos socialmente distantes que se constituíram ao longo do processo de expansão da cidade: o Calabar emergiu na década de 1950 como enclave pobre em meio do primeiro vetor da expansão da classe média e alta; entretanto, o Bate Facho, inserido no segundo vetor de expansão da classe média 
e alta, acompanhou o deslocamento do centro financeiro-comercial-administrativo da cidade para a região do Iguatemi/Tancredo Neves/ Paralela, no final da década de 1970. Já o bairro Vila Verde integra o "Miolo Urbano", cujas regiões fronteiriças com a Avenida Paralela recentemente se tornaram objeto de grandes investimentos públicos em infraestrutura e que acompanharam a construção de grandes condomínios fechados de elite, como o Alphaville 2.

Conquanto vivendo em proximidade geográfica, barreiras físicas mantêm as distâncias sociais entre os moradores dos três bairros populares e o habitantes dos condomínios fechados vizinhos: muros, cercas, entradas protegidas e vigilantes privados patrulhando as ruas adjacentes aos condomínios fechados impedem o acesso a não residentes. Outrossim, o ambiente construído, como a avenida Centenário (Calabar), e barreiras naturais, como a densa floresta tropical que separa fisicamente o bairro Vila Verde do condomínio de luxo Alphaville 2, dificultam as trocas de sociabilidade entre os grupos socialmente distantes. No entanto, é oportuno diferenciar entre, por um lado, o Calabar, bairro inserido em uma região que oferece uma ampla gama de espaços públicos e de lazer, e, por outro, o bairro Vila Verde. Nesse último caso, a ausência de espaços públicos e o alto grau de isolamento espacial do condomínio Alphaville 2 virtualmente impossibilitam as articulações entre os grupos socialmente distantes. Já no Bate Facho, muitos moradores atravessam livremente o Imbuí para se deslocarem até os pontos de metrô e de ônibus, margeando a Avenida Luís Viana Filho.

Entretanto, no caso dos três bairros populares em apreço, as fronteiras assumem um caráter mais simbólico: um ponto de ônibus, um posto de gasolina, um bar ou um prédio abandonado são delimitações facilmente reconhecidas pelos moradores. No entanto, apesar da ausência de barreiras físicas ou de pessoas armadas controlando a entrada dos bairros, pessoas não residentes raramente entram nessas localidades, conforme apontado pela maioria dos entrevistados. Conforme demonstrado pelo Quadro 1, o bairro semiperiférico Bate Facho e o bairro periférico Vila Verde apresentam níveis de vulnerabilidade social ${ }^{7}$ e taxas de homicídio substancialmente mais altos, se comparados com o bairro central ${ }^{8}$ Calabar, corroborando-se o expressivo antagonismo centro-periferia já destacado pelas Figuras 2-4. 
Quadro 1

Perfil Socioeconômico e Situação de Vulnerabilidade Social das Populações dos Três Bairros Analisados

\begin{tabular}{|c|c|c|c|}
\hline ÁREAS DE ESTUDO & $\begin{array}{l}\text { UDH Calabar Alto } \\
\text { das Pombas }\end{array}$ & UDH Bate Facho & UDH Vila Verde \\
\hline $\begin{array}{l}\text { Localização (em } \\
\text { relação à distância do } \\
\text { centro histórico) }\end{array}$ & central & semi-periférica & periférica \\
\hline $\begin{array}{l}\text { Bairros circonferente } \\
\text { das classes média e } \\
\text { alta }\end{array}$ & Barra, Ondina, Graça & Imbui & Alphaville 2 \\
\hline População Total & $\begin{array}{c}10.152 \text { hab. (Calabar: } \\
6,484)\end{array}$ & $\begin{array}{c}1.399 \text { hab. }(\sim 5,000 \\
\text { estimados })\end{array}$ & 8.823 hab. \\
\hline $\begin{array}{l}\text { Renda média per } \\
\text { capita }\end{array}$ & $\mathrm{R} \$ 492,16$ & $\mathrm{R} \$ 330,00$ & $\mathrm{R} \$ 365,26$ \\
\hline $\begin{array}{l}\text { Proporção dos chefes- } \\
\text { de família com grau } \\
\text { superior de educação }\end{array}$ & $4,88 \%$ & $1,40 \%$ & $0,98 \%$ \\
\hline $\begin{array}{l}\text { Mortalidade infantil } \\
\text { por } 1.000 \text { crianças } \\
\text { nascidas vivas }\end{array}$ & 19,05 & 30,2 & 27,6 \\
\hline $\begin{array}{l}\text { Proporção de vul- } \\
\text { neráveis à pobreza }\end{array}$ & $32,30 \%$ & $54,72 \%$ & $50,97 \%$ \\
\hline $\begin{array}{l}\text { Proporção de pessoas } \\
\text { de } 18 \text { anos ou mais } \\
\text { sem fundamental com- } \\
\text { pleto e em ocupação } \\
\text { informal }\end{array}$ & $25,40 \%$ & $42,61 \%$ & $41,89 \%$ \\
\hline $\begin{array}{l}\text { Proporção de crianças } \\
\text { de } 0 \text { a } 5 \text { anos fora da } \\
\text { escola }\end{array}$ & $40,66 \%$ & $49,13 \%$ & $56,21 \%$ \\
\hline $\begin{array}{l}\text { Proporção de pessoas } \\
\text { de } 15 \text { a } 24 \text { anos que } \\
\text { não estudam, não } \\
\text { trabalham e são vul- } \\
\text { neráveis, na população } \\
\text { dessa faixa }\end{array}$ & $9,89 \%$ & $17,08 \%$ & $41,89 \%$ \\
\hline
\end{tabular}


Quadro 1

Perfil Socioeconômico e Situação de Vulnerabilidade Social das Populações dos Três Bairros Analisados (cont.)

\begin{tabular}{lccc}
\hline ÁREAS DE ESTUDO & $\begin{array}{c}\text { UDH Calabar Alto } \\
\text { das Pombas }\end{array}$ & UDH Bate Facho & UDH Vila Verde \\
\hline
\end{tabular}

Proporção de mães

chefes de família sem

fundamental e com

filho menor, no total

$35,86 \%$

$50,29 \%$

$61,88 \%$

de mães chefes de

família

\begin{tabular}{lccc}
\hline $\begin{array}{l}\text { Proporção de crianças } \\
\text { extremamente pobres }\end{array}$ & $7,07 \%$ & $16,11 \%$ & $11,51 \%$ \\
\hline $\begin{array}{l}\text { Taxa de homicídios } \\
\text { por AISPs }\end{array}$ & AISP 14 Barra: 3 & AISP 09: Boca do Rio: 31 & AISP 12: Itapuã: 120 \\
\hline
\end{tabular}

Fonte: Elaboração própria, com base em PNUD (2010)9.

Considerando-se o desigual acesso ao mercado de trabalho e aos serviços urbanos de alta qualidade - seguindo o dualismo centro-periferia - assim como a variabilidade com respeito à vulnerabilidade social das populações dos três bairros, parte-se da hipótese que existe um maior impacto do efeito-território no bairro de Vila Verde. Para o propósito desta pesquisa, foram realizadas 60 entrevistas semiestruturadas no período de novembro de 2018 a março de 2019, com aproximadamente meia hora de duração, em distintos locais do bairro e em diferentes horários. A escolha dos entrevistados ocorreu na sua grande maioria através da intermediação dos líderes comunitários locais; em alguns casos, os entrevistados foram escolhidos de forma aleatória na rua. A amostra integra pessoas de diferentes perfis socioeconômicos, conforme ilustrado pelo Quadro 2. 
Quadro 2

Perfil Socioeconômico dos Entrevistados dos Três Bairros Analisados

\begin{tabular}{|c|c|c|c|}
\hline Bairro & Calabar & Bate Facho & Vila Verde \\
\hline \multicolumn{4}{|l|}{ Sexo } \\
\hline Masculino & 8 & 7 & 10 \\
\hline Feminino & 12 & 13 & 10 \\
\hline \multicolumn{4}{|c|}{ Idade (ciclo de vida) } \\
\hline Abaixo de 18 & 4 & 6 & 3 \\
\hline Entre 18 e 65 & 14 & 13 & 15 \\
\hline Acima de 65 & 2 & 1 & 2 \\
\hline \multicolumn{4}{|l|}{ Renda per cápita } \\
\hline Abaixo de $\mathrm{R} \$ 500$ & 6 & 16 & 14 \\
\hline Acima de $\mathrm{R} \$ 500$ & 18 & 4 & 6 \\
\hline \multicolumn{4}{|l|}{$\begin{array}{l}\text { Proporção } \\
\text { desempregados }\end{array}$} \\
\hline & $25 \%$ & $40 \%$ & $35 \%$ \\
\hline \multicolumn{4}{|c|}{ Nível de escolaridade } \\
\hline $\begin{array}{l}\text { Ensino médio } \\
\text { completo }\end{array}$ & 3 & 1 & 2 \\
\hline $\begin{array}{l}\text { Ensino médio } \\
\text { incompleto }\end{array}$ & 17 & 19 & 18 \\
\hline \multicolumn{4}{|c|}{$\begin{array}{l}\text { Proporção de mães- } \\
\text { chefes de família }\end{array}$} \\
\hline & $60 \%$ & $70 \%$ & $50 \%$ \\
\hline \multicolumn{4}{|l|}{ Com criança menor } \\
\hline & $40 \%$ & $80 \%$ & $60 \%$ \\
\hline
\end{tabular}

Fonte: Elaboração própria ${ }^{10}$.

Realizou-se uma primeira rodada de dez entrevistas que seguiu uma estrutura de questões mais abertas e que já oferecia primeiros insights sobre o contexto sociorresidencial dos entrevistados. Esse procedimento facilitou a elaboração do questionário final ${ }^{11}$ que serviu como ponto de partida para a segunda rodada de entrevistas, enfatizando-se os aspectos considerados como mais relevantes. Após a condução das primeiras entrevistas no Calabar, estabeleceu-se um limite de vinte pessoas por cada bairro. A amostra abrange um espectro de diferentes faixas etárias (cf. Quadro 2). A escolha intencional de uma maior proporção de entrevistados da faixa de "entre 18 e 65 anos" dentro da 
amostra se justifica à luz da assunção que estes já se encontram inseridos no mercado de trabalho formal/informal. Pressupõe-se que podem fornecer importantes informações sobre suas relações empregatícias com os condomínios fechados vizinhos, um dos aspectos-chave deste estudo. A composição da amostra também reflete a distribuição estatística das faixas etárias dentro do bairro analisado, onde predomina uma população jovem (PNUD, 2020).

Procurava-se selecionar um número equânime de entrevistados representando as três faixas etárias (menores de 18 anos; de 18 a 65 anos; e maiores de 65 anos) no intuito de facilitar a comparação entre os três locais. Posteriormente, as entrevistas foram transcritas e submetidas à análise de discurso (incluindo-se a primeira rodada de entrevistas), reproduzindo-se trechos de citação considerados como paradigmáticos para sustentar os argumentos desenvolvidos. As entrevistas foram flanqueadas por observações de campo, realizadas entre janeiro e março de 2019, que viabilizavam a interação direta do pesquisador com os moradores e com as diversas associações, instituições e igrejas do bairro.

Recorremos à técnica de systematic social observation (observação social sistémica) de Sampson (2012) para coletar importantes dados sobre o contexto sociorresidencial das populações dos três bairros, incluindo percursos nas ruas principais e em algumas partes mais recuadas, assim como a observação dos encontros sociais e das atividades comerciais ocorrendo nos espaços "intermediários" localizados entre as três localidades e os bairros vizinhos das classes média e alta, quais sejam: a Avenida Centenário (Calabar), a Praça do Imbuí (Bate Facho) e a Rua das Azaleias (Vila Verde).

Convém ressaltar que os resultados deste estudo possuem um caráter sugestivo e não conclusivo, dado o fato de que se baseiam na percepção subjetiva dos entrevistados, e não em dados quantitativos obtidos a partir de indicadores censitários. Seguindo-se as contribuições metodológicas e epistemológicas do método de estudo de caso ampliado de Burawoy (1998), a pesquisa enfatiza a contribuição da ciência reflexiva para a reconstrução da teoria, atentando para o fato de que essas reconstruções preservam os argumentos centrais da teoria, ao mesmo tempo que absorvem novas anomalias. 


\section{EXAMINANDO O IMPACTO DO EFEITO-TERRITÓRIO EM TRÊS BAIRROS DE SALVADOR}

\section{Dimensão Material}

A pesquisa revela que em todos os três bairros prevalecem deficiências em termos de acesso a escolas, creches, postos de saúde e espaços de lazer, conquanto no Calabar, obtiveram-se as avaliações mais positivas acerca da qualidade dos serviços urbanos locais. Outrossim, atesta-se a escassez de empregos formais dentro do bairro, ainda que a demanda local da população em bens de uso periódico cria oportunidades para microempreendedores. Chama atenção que virtualmente todos os entrevistados - com exceção das pessoas mais idosas - declaram sair diariamente do bairro para estudar, trabalhar e ter acesso a distintos serviços urbanos. Essa dinâmica se contrapõe ao isolamento social observado no caso das populações dos guetos estadunidenses, que, neste contexto, pode ser explicado à luz do fato que tais locais abrangem todas as funções necessárias para sua reprodução social - excetuando-se os postos de emprego (Wilson, 1987).

Entretanto, encontramos diferenças substanciais concernente a infraestrutura social e cultural nos três bairros: enquanto a população do Calabar possui uma longa tradição de engajamento coletivo em favor da comunidade que se consolidou através da atuação da associação dos moradores, dos líderes comunitários e da Biblioteca Comunitária, nos outros dois bairros, os entrevistados apontam a escassez de instituições públicas e filantrópicas, fato que diminui a capacidade de mobilização política da comunidade. Nesse contexto, a ausência de infraestrutura social e cultural suscetível de promover referências sociais positivas - em conjunção com a falta de oportunidades empregatícias e baixos níveis de educação - é considerada um fator que estimula o envolvimento dos jovens em atividades ilícitas, como a venda e o consumo de drogas, conforme já documentado por Wilson (1987) e Kowarick (2009).

Registra-se uma forte variabilidade concernente o "grau de imbricação funcional" das populações dos três bairros: Em Calabar, as amplas oportunidades empregatícias emanam da demanda estável dos vizinhos afluentes em termos de serviços pessoais. Ademais, os entrevistados assinalam as vastas oportunidades de venda ambulante 
de bebidas, comidas, lanches, frutas e verduras nas praças públicas vizinhas, em frente aos apartamentos residenciais das classes média e alta e nas praias da Barra e Ondina.

Contrastando com esta relação consolidada entre oferta e demanda, os entrevistados de Bate Facho declararam que as articulações com os moradores do bairro vizinho Imbuí pelo viés empregatício declinaram nos últimos anos, em função: (1) da redução da oferta de serviços pessoais como resultado da crise econômica; (2) das alterações na legislação de trabalho da empregada doméstica com carteira assinada, que encareceu as despesas salariais para o empregador; e (3) da maior estigmatização territorial da população em decorrência do aumento do tráfico de drogas na região. Essa diminuição das oportunidades empregatícias no setor dos serviços pessoais, que, durante muitos anos, haviam garantido uma renda relativamente estável aos moradores do Bate Facho, é corroborado por mais da metade dos entrevistados, entre outros, Raimundo, que atualmente trabalha como vigilante em um condomínio fechado do Imbuí:

Acho que a maioria daqui veio para o Bate Facho por conta do trabalho nos condomínios vizinhos. Empregavam muita gente daqui e isso nos permitia de melhorar nossas casas, botar nossos filhos para o colégio em vez de mandar eles trabalharem desde cedo. Mas com essa crise, que já dura alguns anos, a dona do apartamento faz sua própria faxina, cozinha, faz tudo que nós fizemos antes. Também a criminalidade aqui aumentou e eu acho que eles desconfiam da gente, acham que é tudo ladrão quem mora aqui (Raimundo, um vigilante de 58 anos).

O caso de Bate Facho também ilustra que, ao contrário do Calabar, a inserção do bairro em uma região economicamente dinâmica não se traduz automaticamente em maiores chances de participação social da sua população, conforme pressuposto pela hipótese das "externalidades positivas" (Sabatini e Salcedo, 2007). No caso do Imbuí, trata-se de um bairro composto majoritariamente de prédios residenciais, enquanto na região Iguatemi-Tancredo Neves-Paralela, que concentra a grande parte dos edifícios empresariais da cidade, os espaços públicos são fortemente disputados pelos vendedores ambulantes de outros bairros mais próximos, situação que provoca um grande número de conflitos. Convém ressaltar que a maioria dos empregos oferecidos nessa região exige pelo menos a conclusão do Ensino Médio e, no caso dos serviços mais especializados, um diploma de educação superior, um critério que a grande parte da população do Bate Facho não pode 
cumprir. A falta de possibilidades de oferecer produtos não duráveis em frente aos prédios de apartamentos do Imbuí deve ser explicada à luz da maior presença de vigilantes privados na rua, que impedem a atuação de vendedores ambulantes, conforme observado por Daniel:

Olha, aqui quase não tem como vender frutas como antigamente. Às vezes até tem viatura da polícia rodando nas ruas do Imbuí. Acho que estão com medo da gente, assistem televisão e pensam: ah, estes aí são todos assaltantes e traficantes! (Daniel, 42 anos, desempregado).

Essa afirmação, compartilhada por outros entrevistados do Bate Facho, frisa o papel da mídia televisiva na propagação de uma imagem negativa do bairro associada ao tráfico de drogas (Sampson, 2012), uma dinâmica que, segundo os entrevistados, prejudica sua procura de emprego. A crescente tendência de exclusão dos moradores do Bate Facho do espaço público também é atestada por outros entrevistados, ao exemplo da Praça do Imbuí - conjunto de bares e restaurantes localizado nas imediações do bairro - que durante os últimos anos se tornou objeto de obras de requalificação urbana. Segundo Jéssica, essas reformas acarretaram na "elitização" da localidade, sendo que os moradores do Bate Facho amiúde são discriminados na hora de frequentar os bares ou são impedidos de vender seus produtos pelos donos dos estabelecimentos que temem um aumento de assaltos na região:

Quantas vezes eu já tentei de vender meus lanches nesta praça lá! Sempre que eu vou lá sou barrada pelos funcionários dos bares. Acho que este lugar mudou muito, antigamente era para todo o mundo e dava para ganhar um bom dinheiro. Hoje, quem frequenta é a classe média e estes querem viver em conforto e segurança, enquanto o preço da cerveja duplicou. Não vou mais! (Jéssica, 56 anos, diarista).

Essa entrevista também mostra como a conversão da Praça do Imbuí em zona de entretenimento da classe média contribuiu ao encarecimento dos produtos ali vendidos, circunstância que levou os moradores do Bate Facho a frequentarem os bares locais onde encontram preços mais acessíveis e que diminuiu as possibilidades de troca de sociabilidades com os habitantes do Imbuí. Conforme relata Mário, eram particularmente as conversas informais na mesa de bar com os moradores dos condomínios que abriam oportunidades para realizar algum trabalho, como lava-jato, limpar o apartamento, consertar uma máquina, etc. 
Uns cinco anos atrás ainda, era bem simples achar um emprego: tomar uma cerveja na Praça do Imbuí! Ao final de contas, tanto a gente do Bate Facho quanto os habitantes destes condomínios do Imbuí frequentavam estes bares da Praça. Facilitava muito, porque sentávamos juntos à mesa e conversávamos. Destes encontros muita gente daqui saiu com emprego na mão (Mário, um jardineiro de 66 anos).

Enquanto os moradores do Bate Facho afirmam encontrar crescentes obstáculos na hora de procurar um emprego dentro dos condomínios vizinhos do Imbuí, no bairro de Vila Verde, os entrevistados declaram se sentir explorados como mão-de-obra barata pelo Hangar Business Park e pelo Norte Shopping, maior polo de emprego da região. Conforme Rose, as empresas localizadas na sua vizinhança aproveitam da situação de vulnerabilidade da população para baixar os salários e frequentemente incorrem em práticas de discriminação:

Sim, eu já trabalhei neste hotel. Mas eu fiquei surpreendida quando vi os baixos salários que eles pagam para o trabalho de camareira, eu até ganho mais vendendo lanches no ponto de ônibus. E depois que o governo reformou estas avenidas e botou o metrô todo parece ter ficado mais caro, o salário de camareira não acompanhava mais. Mas o que realmente me fez sair deste emprego foram as suspeitas de eu ter roubado toalhas dentro do hotel, que absurdo! (Rose, 25 anos, vendedora ambulante).

Rose introduz duas temáticas que frequentemente surgiram nas entrevistas com os moradores do Vila Verde, quais sejam, os baixos salários pagos no setor de serviços não qualificados e o encarecimento do custo de vida do bairro, principalmente depois da construção do condomínio Alphaville 2 e da conclusão das diversas obras viárias na região. $\mathrm{O}$ aumento das despesas resulta principalmente da imposição de impostos de IPTU posterior à regularização do título de posse de moradia e da maior "formalização do bairro", conforme observado por Andréia, uma doméstica de 42 anos, referindo-se à implementação de distintos serviços públicos, como coleta de lixo e sistema de esgoto.

Contrastando com as oportunidades empregatícias destacadas por Salcedo e Torres (2004), nenhum dos entrevistados declara estar trabalhando atualmente dentro do condomínio de elite vizinho Alphaville 2. Conforme os depoimentos, no início da construção deste condomínio, a população 
do Vila Verde criava grandes expectativas com a chegada de famílias com maior poder aquisitivo na região e apostava em uma rápida valorização do seu próprio bairro, conforme demonstra o relato seguinte:

Tinha que ver a alegria quando soubemos que esta Alphaville 2 iria se instalar na nossa região! Acho que no fundo esperávamos maiores chances de emprego. Agora, a realidade é outra: tentamos tanto entrar nestes condomínios e oferecer - quase de graça - nosso trabalho, e nada! (Eduardo, 54, eletricista).

Várias entrevistas testemunham das tentativas frustradas de oferecer sua mão-de-obra na construção civil. Contrariando as expectativas iniciais, a empresa imobiliária responsável recrutou os operários de bairros mais distantes, alegando que não havia mais vagas para a população do Vila Verde. Conforme os depoimentos, os moradores nem conseguiam ter acesso ao condomínio, sendo sua entrada barrada pelos porteiros do condomínio. Essa falta de acesso ao condomínio ainda se vê agravada pela ausência de espaços públicos suscetíveis de facilitar a instalação de pequenos estabelecimentos para a venda informal de produtos, sendo que o ostensivo patrulhamento de vigilantes e a própria estrutura do Alphaville 2 - contando com uma longa estrada de entrada que permite apenas a circulação de carros - impedem o desempenho de atividades comerciais.

\section{Dimensão Social}

No caso de Calabar, observa-se uma forte tendência de orientação extralocal dos entrevistados vis-à-vis seus bairros vizinhos das classes média e alta, dado o fato que a maioria das funções necessárias para sua reprodução social está localizada fora do bairro (Hannerz, 1980). Esta circunstância confere um maior grau de diversidade interna e dispersão territorial aos vínculos sociais, e, portanto, favorece o acesso a informações extralocais sobre vagas de emprego (Wilson, 1987). Contudo, o acesso a este tipo de redes sociais pode ser confirmado apenas no grupo dos entrevistados que regularmente sai do seu bairro dentro das suas trajetórias casa-escola, casa-trabalho, casa-espaços de lazer/ recreação, como no caso de Lucas:

Bom, eu só volto para Calabar durante a noite. Durante o dia inteiro eu vendo lanches e bebidas nas praias da Barra e Ondina. Eu chego a conhecer 
muita gente e muitas pessoas me perguntam se eu não conheço alguém que possa fazer uns consertos baratos nos condomínios (Lucas, 26, atendente de uma loja de shopping).

Entretanto, as redes sociais dos entrevistados trabalhando no próprio bairro, assim como das pessoas mais idosas, apresentam uma estrutura mais encapsulada, já que preponderantemente constituídas por parentes, amigos e vizinhos locais. O acesso a informações também está condicionado ao contato frequente a amigos e parentes já trabalhando nos condomínios, particularmente os porteiros, que frequentemente são informados pelos donos dos apartamentos quando necessitam serviços de diarista, eletricista ou jardineiro.

Já no Bate Facho, a estrutura das redes sociais revela um elevado grau de localismo, confirmando-se uma correlação entre, por um lado, altos níveis de crime e de vulnerabilidade social e, por outro lado, uma estrutura encapsulada das redes sociais, conforme já atestado por Wilson (1987). Em contraste ao Calabar, o baixo grau de autonomia funcional do bairro não promove uma orientação extralocal dos entrevistados vis-à-vis seus arredores, suscetível de alavancar sua integração econômica dadas as esparsas possibilidades de usar o espaço público do Imbuí para a venda de produtos não duráveis.

Observa-se, por um lado, a predominância de vínculos sociais primários promovendo a coesão social e a estabilização da situação econômica ao curto prazo e, por outro lado, a forte presença de vínculos sociais tecidos nas distintas igrejas evangélicas do bairro. Em diferença ao Calabar, os vínculos primários não funcionam como alavanco para a integração econômica dos entrevistados - situação que deve ser explicada à luz da alta taxa de desemprego que contribui para a sua dissociação vis-à-vis das redes tecidas no ambiente do mundo do trabalho formal. Por outro lado, virtualmente todos os entrevistados afirmam receber periodicamente pequenas doações de comida e suporte social pelos seus vizinhos ou pela igreja, quando em situação de emergência, uma dinâmica que não se comprova no Calabar. Esse sistema de suporte se tornou particularmente importante para a população na ocasião das enchentes de 2008, quando todos os moradores do Bate Facho se entreajudavam, como observa Michelle:

Temos uma forte rede de suporte aqui pelo menos em situações de emergência, como nas enchentes de 2008. Todo mundo oferecia sua ajuda aos 
vizinhos que tinham perdido seus móveis ou sua casa inteira. Acho que isso é uma das coisas positivas desta comunidade, todo mundo se entreajuda (Michelle, 26 anos, diarista).

Esta observação, compartilhada por muitos entrevistados, ilustra como a falta de infraestrutura e de serviços públicos pode ser parcialmente recompensada por um sistema coeso de suporte e reciprocidade entre os vizinhos que atuam em situações de emergência (Moser, 1998; Perlman, 2010), uma qualidade unanimemente percebida como positiva pelos moradores. Contrariando a hipótese de Sampson (2012) acerca da correlação positiva entre a privação de recursos institucionais e o enfraquecimento da capacidade de collective efficacy da comunidade, observa-se um alto nível de disposição de intervir regularmente quando se instala uma briga entre os vizinhos ou quando os adolescentes vizinhos "andam com a galera errada" em vez de estar na escola. A eficiência dessas estratégias de prevenção ao crime e controle social informal se explica, segundo Josilene, líder comunitária do bairro, à luz do fato que "sempre tem alguém em casa para olhar a rua" e do alto grau de intimidade dos moradores: na sua grande maioria, chegaram no Bate Facho na década de 1960 e construíram suas moradias precárias através de esforços coletivos. Essa maior disposição de prestar ajuda ao vizinho e de se engajar em prol do bem-estar coletivo da comunidade também foi destacada pelos entrevistados mais idosos do Calabar, que lamentam a perda dessa forma de solidariedade comunitária na geração mais nova, uma vez que as reinvindicações mais urgentes já foram atendidas.

No bairro de Vila Verde registra-se uma expressiva tendência de recuo às esferas primárias de sociabilidade de família e parentes, mesmo controlando pelos níveis de renda, educação, status ocupacional e idade. Como Pedro comenta, um dos motivos que explica este encapsulamento remete à disputa entre duas facções criminosas rivais pelo tráfico de drogas na região que deixou os moradores mais seletivos na escolha de amizades:

Faz poucos anos eu fazia muitas coisas com meu tio e meus sobrinhos que vivem neste bairro e todo mundo ajudava todo o mundo quando faltava dinheiro. Mas logo quando estes se envolveram no tráfico de drogas eu cortei o contato. Eu perdi todos meus contatos, mas eu não podia mais confiar neles (Pedro, 52 anos, carpinteiro). 
Como podemos deduzir deste depoimento, o distanciamento de Pedro dos seus parentes causou a perda de importantes contatos sociais que podiam ser mobilizados em tempos difíceis, mas o medo de andar "com as pessoas erradas" prevaleceu na sua decisão. A alta incidência de crimes violentos tende a enfraquecer os mecanismos de controle social informal, como o monitoramento e o controle dos adolescentes que não frequentam a escola ou que "andam com a galera errada", dado o medo de sofrer as represálias dos traficantes. Dentro das nossas visitas ao bairro, observamos que depois das 19:00 poucas pessoas se encontravam na rua, dado também o fato que, na sua grande maioria, os bares e o comércio local já se encontravam fechados. Indagados sobre tal situação, mais da metade dos entrevistados respondeu que não iria se "aventurar" na rua depois do escurecer, dado o medo de se tornar vítima de confrontos entre os traficantes. Convergindo com os postulados de Sampson (2012), os entrevistados apontam para uma substancial desestabilização da organização social da comunidade como resultado do aumento do crime, que, em contrapartida, reduz a disposição dos entrevistados de intervirem em favor do bem-estar coletivo da comunidade. Essas dificuldades de confrontar grupos criminosos locais contribuíram para uma intervenção mais agressiva da polícia, que aumentou sua presença na região desde a construção do condomínio Alphaville 2. Essas duas dinâmicas são estreitamente interligadas já que, conforme atestado por Sampson (2012), a ausência de solidariedade intracomunitária enfraquece o poder da população de confrontar os grupos criminosos locais, fato que se traduz em uma menor disposição de cooperar com a polícia.

Já no Calabar, os entrevistados enfatizam a importância das medidas informais de prevenção do crime realizadas, por um lado, pela BCS, as igrejas protestantes e a Biblioteca Comunitária e, por outro lado, pelos líderes comunitários. Essas instituições também promovem uma ampla gama de recursos (não) materiais, como a distribuição de comida, pequenos empréstimos, suporte emocional e até cursos de capacitação profissional.

Maiores paralelas entre os três bairros se delineiam com respeito às articulações dos entrevistados com os moradores dos seus bairros vizinhos da elite. As observações de campo demonstram que, em todos os três locais investigados, relações não empregatícias entre os grupos socialmente distantes são escassas ou completamente ausentes - como demonstrado no caso de Vila Verde - com a exceção do Calabar, onde foram observados contatos espontâneos que se produzem a partir do 
uso compartilhado dos equipamentos ginásticos da Avenida Centenário, da frequência das praias vizinhas da Barra e Ondina e do uso dos mesmos supermercados e do Shopping Barra. Entretanto, práticas discriminatórias podiam ser observadas no uso compartilhado do playground infantil público localizado entre o Imbuí e o Bate Facho. Esse espaço tem sido palco de constantes conflitos intervizinhais sobre seu uso, instigados pelas tentativas dos moradores do Imbuí de impedir o acesso às crianças do Bate Facho a partir do encercamento do local.

\section{Dimensão Simbólica}

Em Calabar, destaca-se a estigmatização territorial da sua população apesar das melhorias realizadas em termos de segurança pública e de combate ao tráfico de drogas, atribuídas majoritariamente à atuação da BCS no local. Os entrevistados recorrem a distintas estratégias para se desassociar da imagem do tráfico de drogas que consistem em distinguir entre, por um lado, o grupo de trabalhadores honestos, e, por outro lado, o grupo de habitantes envolvidos em atividade criminosas

Essas estratégias de diferenciação se dirigem principalmente contra as reportagens midiáticas consideradas como "enviesadas" pelos entrevistados que enfocam unilateralmente aspectos negativos, como roubos e assaltos na região que imediatamente são atribuídas à conta do Calabar. A dificuldade de combater a imagem da "invasão" no discurso público se vê agravada pela estrutura física fechada do bairro, que conta com apenas duas entradas principais carroçáveis. Essa situação dificulta a entrada de pessoas extralocais que, "uma vez que conhecem o bairro, iriam ver que aqui é tranquilo e iriam largar seus preconceitos", conforme aponta André, um estudante de 16 anos.

Esse isolamento geográfico também pode ser observado no caso de Bate Facho, bairro que se estende por uma rua principal de quase dois quilômetros e que possui apenas um acesso na altura da Avenida Jorge Amado e outro pelo Imbuí. Ainda que se trate de fronteiras simbólicas que contrastam com as barreiras físicas caracterizando os condomínios fechados que restringem o acesso a moradores, funcionários e visitantes - o fechamento dos bairros se ergue em barreira para o estabelecimento de contatos com pessoas não locais que, segundo Maria, uma vendedora ambulante de 26 anos, "não têm nenhum motivo para entrar aqui". Novamente, atribui-se uma forte responsabilidade à mídia televisiva 
na reprodução de uma cultura de medo que, segundo Alexa, estudante de 17 anos, já fez vários amigos moradores de outros bairros desistirem de visitá-la.

Em alinhamento com as observações de Kowarick (2009) e Ruiz-Tagle (2016), os entrevistados apontam diferentes formas de discriminação na procura de emprego, mas também ressaltam o tratamento enviesado da polícia e dos agentes públicos. Segundo os depoimentos, a estigmatização territorial cria obstáculos ao acesso a determinados serviços, como televisão, internet e o transporte alternativo privado, sendo que alguns funcionários se recusam a entrar no bairro até durante o dia, alegando os altos níveis de violência. A principal estratégia de contornar estas práticas discriminatórias na procura de emprego consiste em colocar um endereço de residência diferente, conforme apontado por Joana:

Eu coloco Imbuí na procura da vaga de emprego. A maioria nem sabe onde fica o Bate Facho, mas se eles conhecem meu bairro eles dizem: ah, é ali onde teve aquela chacina, lá você mora? Então realmente ajuda porque o CEP daqui é o mesmo que no Imbuí (Joana, 24 anos, faxineira).

Essa estratégia de contornar o estigma territorial através da indicação do CEP do bairro Imbuí também é apontado pelos estudantes entrevistados, que afirmam se sentirem menos confortáveis na escola ou na universidade se professores e colegas de estudo souberem onde eles moram.

Também no caso do Vila Verde atesta-se a existência de uma série de estigmas que afetam negativamente a integração econômica da população local e que se atrela à imagem negativa dos bairros vizinhos de Mussurunga e São Cristóvão, considerados como bastiões do tráfico de drogas. Ademais, registra-se um aumento dos controles policiais desde a chegada do condomínio fechado de Alphaville 2 na região, que são percebidos como ameaça física pela população residente, já que os policiais não diferencem entre "quem parece ser um bandido" e quem "é um homem trabalhador", segundo afirma Ivan, 25 anos, que trabalha como porteiro em uma loja no Norte Shopping.

Com respeito à percepção subjetiva dos entrevistados acerca do seu local de moradia e do seu entorno geográfico, observa-se que o sentimento de pertencer ou estar excluído das regiões economicamente mais dinâmicas de Salvador - ou de habitar uma região que se encontra 
em pleno processo de valorização, como no caso da Vila Verde - se atrela às possibilidades de participação socioeconômica no seu entorno geográfico, tanto como funcionário dos condomínios fechados/apartamentos quanto como vendedor ou usuário dos espaços públicos.

Subsequentemente, registra-se o maior grau de identificação e de satisfação de morar no bairro no caso do Calabar, de onde "ninguém sai sem um bom motivo" (Ana, 18 anos, babá), dada sua proximidade aos principais mercados de trabalho e a um dos pontos turísticos mais populares da cidade: as praias da Barra. Essa percepção de amplas oportunidades de participação social, que decorrem do uso funcional residencial, comercial e público dessa região, declina nos outros dois bairros localizados em proximidade aos bairros da classe média e alta, onde predomina o uso residencial do espaço e onde os vendedores ambulantes e microempreendedores são vedados de usar o espaço público para o comércio informal.

Independentemente do grau de imbricação funcional da população vis-à-vis seu entorno geográfico, em todos os três bairros, as fronteiras físicas e simbólicas se encontram internalizados por um discurso similar que distingue entre diferentes mundos de vida e que destaca o desigual acesso a estruturas de oportunidades, particularmente com respeito às diferenças qualitativas no sistema de educação (superior) mas também em relação ao sistema de saúde e segurança. Esse fenômeno abstrai da dimensão espacial das desigualdades já que remete ao próprio sistema de estratificação social no Brasil, conforme apontado pela líder comunitária Josilene, que, ao ser questionada sobre as possibilidade de entreter vínculos sociais mais duradouros com os moradores do Imbuí fora da relação empregatícia, respondeu: "Aqui nunca teve isso. É cada um no seu quadrado".

No Calabar, a ausência de controles ostensivos de segurança a as amplas oportunidades de participação no espaço público podem explicar o fato que os moradores das classes média e alta não são percebidos com inveja ou frustração pelos entrevistados, senão como "trabalhadores honestos que conseguiram alcançar seus objetivos à base de longos anos de estudos", conforme observado por Eduardo, 19 anos, graduando em engenharia civil. Convém frisar que a maioria dos entrevistados precisa atravessar os bairros circunferentes das classes média e alta para acessar outras partes da cidade e recursos materiais, uma dinâmica que promove um contato físico frequente - mesmo que superficial - entre 
os grupos socialmente distantes. Essa situação não se comprova no caso dos moradores do Alphaville 2, que permanecem praticamente invisíveis para os entrevistados do Vila Verde.

Mesmo que o condomínio Alphaville 2 esteja separado fisicamente por uma floresta tropical do Vila Verde, suas mansões luxuosas deixam as clivagens socioeconômicas mais expressivas e disseminam a inveja e revolta na população pobre. A chegada das famílias abastecidas é majoritariamente percebida como uma ameaça de uma iminente expansão do condomínio de luxo em direção do Vila Verde. Alguns moradores comentaram que o recente investimento público em infraestrutura viária, como a construção da Avenida 29 de Março e da estação de metrô Bairro da Paz, contribuiu ao aumento das despesas de aluguel. Essa situação, ao longo prazo, pode forçar seu deslocamento para bairros do "Miolo Urbano". Mais distantes da Avenida Paralela, "onde ainda é possível construir sua casa própria sem gastar com luz, água, esgoto e coleta de lixo, serviços que aqui são de péssima qualidade", como afirma Maria, aposentada de 68 anos. Diferentemente do caso de Calabar, os investimentos públicos em serviços de alta qualidade são percebidos como benefícios exclusivos dos moradores dos condomínios vizinhos, que contrastam com a frequente falta de água e luz do próprio bairro.

Entretanto, no Bato Facho, a gradativa expulsão dos moradores da Praça do Imbuí e a tentativa de encercamento do playground infantil são percebidas como tentativas de exclusão do espaço público (Janoschka e Sequera, 2016). Segundo Jacqueline, o sentimento de estar vedado de utilizar os espaços de lazer na vizinhança pode ter contribuído ao aumento das tensões entre os moradores e o aumento de assaltos e roubos na região:

Eu acho que isso de tirar a gente deste playground, onde nossas crianças e as crianças do Imbuí brincavam juntos durante anos, causou muita indignação aqui no Bate Facho. Isso fez com que muitos jovens daqui não respeitem mais os moradores dos condomínios. Essa raiva de se sentir excluído já motivou muitos assaltos e roubos nas ruas do Imbuí (Jacqueline, uma estudante de 17 anos).

Já para outros entrevistados, como Caroline, uma faxineira de 27 anos, a revitalização da Praça do Imbuí é percebida como uma ameaça latente de ser expulso do seu bairro e de ser forçado a morar em bairros mais 
distantes onde eles estariam mais isolados dos mercados de trabalho. $\mathrm{O}$ medo de expropriação, já atestado por Kowarick (2009), se fundamenta na vulnerabilidade da população vis-à-vis a falta de regularização de título de posse da moradia que afeta principalmente os moradores das porções mais recuadas do bairro.

\section{DISCUSSÃO DOS RESULTADOS}

Corroborando com nossa hipótese incialmente levantada, o impacto do efeito-território está correlacionado às variáveis: distância geográfica ao mercado de trabalho e índice de vulnerabilidade social da população e incidência de homicídios, observando-se uma incidência maior nos bairros (semi) periféricos de Bate Facho e Vila Verde. Evidenciam-se estreitas causalidades entre as dimensões material, social e simbólica do efeito-território, sendo que, por exemplo, deficiências em termos de segurança pública impactam negativamente na procura de emprego, nos padrões de sociabilidade, na capacidade de collective efficacy e na autopercepção dos entrevistados. Inferindo a partir dos resultados empíricos, três mecanismos intervenientes podem explicar a variabilidade do impacto do efeito-território nos três bairros analisados, quais sejam: as alterações no sistema primário de suporte, o impacto do crime e a estigmatização da população.

O primeiro mecanismo se atrela tanto a transformações macrossociais, como as mudanças na composição da família e um generalizado declínio da mobilização coletiva dos moradores em favor de um etos mais individualista, quanto a fatores essencialmente espaciais, como altos níveis de desemprego e a privação de recursos institucionais. Evidenciando maiores convergências com o contexto urbano estadunidense (Sampson, 2012; Wilson, 1987), o Bate Facho demonstra que a baixa capacidade de mobilização política - de crucial importância para a reinvindicação de investimentos públicos em infraestrutura e serviços públicos locais - prejudica a integração socioeconômica da população, principalmente considerando a falta de escolas e creches locais. Por um lado, esse vácuo institucional deixado pelo Estado foi sendo preenchido pelas igrejas evangélicas, que promovem uma série de recursos (não)materiais aos seus membros. Contudo, essas falham em fortalecer a capacidade de coesão interna da comunidade, dada a forte concorrência entre as distintas congregações. Por outro lado, a ausência do Estado foi preenchida por estruturas criminosas que se infiltraram na organização social da comunidade. Essa situação se 
comprova particularmente no caso de Vila Verde enquanto a grande vitalidade do sistema primário de suporte observado no Bate Facho beneficia o acesso a recursos (não)materiais em situações de emergência e reforça a capacidade de collective efficacy da comunidade.

O segundo mecanismo remete ao impacto do crime nas chances de integração econômica do indivíduo, nos seus padrões de interação, e na imagem territorial do bairro. Conquanto não se comprove a difusão de um estilo de comportamento próprio ao gueto, conforme documentado pelos pesquisadores estadunidenses (Sampson, 2012; Small e Feldman, 2012), virtualmente todos os entrevistados - excetuando-se os moradores do Calabar - declaram estar sofrendo de um forte impacto do crime nas suas rotinas diárias. A exposição a grupos de pares afiliados ao tráfico de drogas afeta principalmente os segmentos mais jovens do bairro Vila Verde, enquanto, no Calabar, as instituições públicas e privadas e, no Bate Facho, o sistema de suporte entre os vizinhos logram mitigar este efeito.

O terceiro mecanismo se atrela à estigmatização territorial da população. A forte associação entre atributos sociais e espaciais na avaliação do "outro" (Wacquant, 2016) favorece a reprodução de distintas práticas de discriminação territorial, uma situação que afeta negativamente a procura de emprego e a interação com indivíduos não residentes do bairro. Nesse aspecto, obtiveram-se os resultados mais convergentes entre os três bairros, fato que frisa a necessidade de integrar a percepção subjetiva dos entrevistados sobre processos e mecanismos de exclusão (Bourdieu, 1979).

Nessa pesquisa, o fator de proximidade espacial a bairros das classes média e alta foi tratado como variável condicional, que pode sofrer alterações ao longo do tempo de "convivência". Por um lado, o estudo evidenciou que, apesar da proximidade a serviços urbanos de alta qualidade (como hospitais, creches e escolas da rede privada), prevalecem as estruturas de segmentação social, particularmente evidentes na bifurcação entre um sistema público e privado com respeito aos cuidados de saúde, educação e segurança, conforme já amplamente discutido na literatura pertinente (Bayón e Saraví, 2013; Kaztman e Retamoso, 2006). Nesse caso, a variabilidade entre os três bairros deve ser explicada à luz das possibilidades do uso compartilhado do espaço urbano e do grau de isolamento físico dos condomínios fechados (Janoschka e Sequera, 2016). 
Apenas no caso do Calabar comprovam-se as "externalidades positivas" que, conforme Galster e Killen (1996) e Sabatini e Salcedo (2007), emanam da proximidade a grupos sociais de alto status socioeconômico. Essas vantagens locacionais se referem à dinamização das articulações interclasse - através do uso compartilhado de determinados espaços de lazer e áreas públicas - que beneficia a integração econômica dos seus moradores. O Calabar também é o único bairro cuja população usufrui da proximidade a serviços urbanos de maior qualidade, como escolas, universidades, creches e hospitais da rede pública. Todavia, essa vantagem locacional está mais atrelada à localização estratégica do bairro em proximidade ao centro da cidade, que recebe maiores investimentos em serviços públicos, do que ao uso desses serviços junto com os estratos sociais mais altos - que recorrem a serviços privados. Entretanto, não se comprovaram as "externalidades positivas" com respeito ao fortalecimento do controle social informal da comunidade e à exposição a modelos de referência social da classe média.

Por outro lado, a pesquisa demonstrou que a imbricação funcional pelo viés empregatício não pode ser considerada como resultado "automático" da proximidade espacial entre grupos socialmente distantes: os dois bairros Calabar e Bate Facho têm em comum que seus moradores se beneficiavam da grande demanda que emergia tanto no setor da construção civil dos prédios de condomínios de elite quanto no setor dos serviços pessoais desempenhados nos condomínios. Contudo, registra-se um declínio dessa relação "simbiótica" que - em diferença aos contextos estadunidense e europeu - havia viabilizado a integração de grandes contingentes populacionais de baixa renda tradicionalmente excluídos do mercado laboral formal. Tanto o aumento do crime violento quanto a exclusão dos moradores pobres dos espaços públicos - suscetíveis de promover um maior contato com os vizinhos das classes média e alta - explicam esse declínio.

Ambas as observações relativizam o papel explicativo do fator de proximidade espacial de populações de baixa renda a bairros das classes média e alta para sua integração socioeconômica e, ergo, para a atenuação do efeito-território, já que remetem às disparidades intrínsecas à própria organização socioespacial da cidade, com respeito ao acesso aos mercados de trabalho e serviços urbanos de alta qualidade, que varia em função da distância do bairro às regiões centrais de Salvador. Convém ressaltar que os desafios da sua integração socioeconômica que está na base da discussão em curso sobre a eficiência das políticas 
de social mixing (Galster, 2007; Ludwig et al., 2008) - se reportam à complexa imbricação causal entre três dimensões, quais sejam: (1) o indivíduo e seus recursos de atuação (dimensão micro); (2) o contexto sociorresidencial no qual se insere (dimensão meso) - que engloba as variáveis: mercado laboral e habitacional local, acesso a infraestrutura e a serviços urbanos, formas de organização social e institucional e capacidade de mobilização política da comunidade; e (3) as estruturas socioeconômicas, culturais e político-históricas mais amplas (dimensão macro). Essas três dimensões abrangem as políticas sociais, habitacionais e de bem-estar, o sistema de estratificação social e distintas formas institucionalizadas de discriminação racial.

Tais considerações possuem importantes implicações para a elaboração de políticas visando a integração socioeconômica de famílias pobres que, em vez de nortear-se em people-based ou place-based policies deveriam se fundamentar em uma aproximação mais holística às desigualdades sociais em consonância com as premissas do indirect approach, atentando-se ao fato que os custos da concentração de desvantagens estruturais na escala do bairro não são arcados exclusivamente pelos seus moradores pobres senão pelos membros de todas as classes sociais. Particularmente, a segmentação social - favorecendo a reprodução de distintas práticas de discriminação que decorrem da falta de contato com o "outro" - abstrai da dimensão microssocial e, portanto, precisa ser analisada à luz do sistema vigente de estratificação social (Butler e Robson, 2003; Wacquant, 2016).

Nesse contexto, abrem-se interessantes caminhos para a abordagem das configurações socioespaciais caracterizadas pela proximidade espacial entre grupos socialmente distantes a partir do conceito de "mundos de viver", de Husserl (1970), atentando-se para o fato que as articulações entre os moradores dos três bairros e os habitantes dos condomínios vizinhos de elite se atrelam às percepções subjetivas sobre as possibilidades de participação socioeconômica e às próprias barreiras do ambiente construído (Davidson, 2010). Marcuse e Van Kempen (2000) sugerem a metáfora da layered city em referência à superposição de diferentes formas de apropriação espacial e temporal de esferas de vida (layers). Essa divisão demonstra que os moradores dos três bairros e os habitantes dos condomínios vizinhos convergem fisicamente dentro da esfera de trabalho (funcionários dos condomínios, dos shoppings e hotéis), enquanto se mantêm inalteradas as distâncias nas demais esferas, como no caso do lugar de moradia, acesso 
a serviços urbanos e de lazer etc. Esse modelo explicativo enfatiza que a crescente fragmentação da organização socioespacial das cidades estadunidenses, caracterizada por configurações de proximidade espacial entre grupos socialmente distantes que se originam a partir de processos de gentrificação da inner-city, não promove necessariamente uma maior integração socioeconômica das camadas baixas ou grupos étnico-raciais minoritários (Lees et al., 2008).

\section{CONSIDERAÇÕES FINAIS}

O estudo visou explorar o impacto do efeito-território nas condições de vida dos moradores de três bairros populares de Salvador, indagando-se sob quais condições a proximidade espacial a bairros de elite amplia as possibilidades de integração socioeconômica. Identificamos três mecanismos operando na escala do bairro (quais sejam: as alterações no sistema primário de suporte e o impacto do crime e a estigmatização da população) cujas estruturas comuns, correlações causais similares, mas também cuja variabilidade podem dar importantes impulsos para pesquisas comparativas. Esse estudo frisa o potencial da criação de espaços públicos e do combate ao tráfico de drogas para o fortalecimento das articulações (não) empregatícias entre os grupos socialmente distantes.

No Brasil, apesar da forte evidência que tanto a extrema pobreza quanto a extrema riqueza tendem a ser espacialmente mais concentradas desde a abertura da economia nacional para os mercados globais na década de 1990, pesquisas sobre o efeito-território ainda permanecem um desideratum. O debate sobre as implicações da concentração das desvantagens estruturais em bairros fortemente segregados para o planejamento urbano ainda é incipiente e denota a falta de diálogo entre pesquisas empíricas e políticas públicas.

De particular relevância para a análise de processos de gentrificação na Sociologia Urbana Brasileira, o caso da Alphaville 2 ilustra que a construção de comunidades fechadas contribuiu à transformação social e espacial das regiões fronteiriças do "Miolo Urbano", através da implementação de novos polos de concentração espacial das camadas altas. Esses abrangem edifícios residenciais, zonas de entretenimento e corporate business towers - como o Hangar Business Park - e contam com grandes investimentos públicos em infraestrutura viária. Em Salvador, a tendência se materializa em regiões (semi) periféricas 
localizadas fora do tradicional vetor de expansão das classes média e alta da Orla Atlântica, conforme ilustra a Figura 5, ao exemplo do que pode ser denominado "Polo Alphaville II" e do "Polo Horto Bela Vista". Nessas regiões, observa-se a concentração de investimentos privados, destacando-se o Shopping Bela Vista e o Salvador Norte Shopping, grandes supermercados e concessionários de carros.

Figura 5

Novos Polos de Concentração da Classe Média e Alta em Salvador

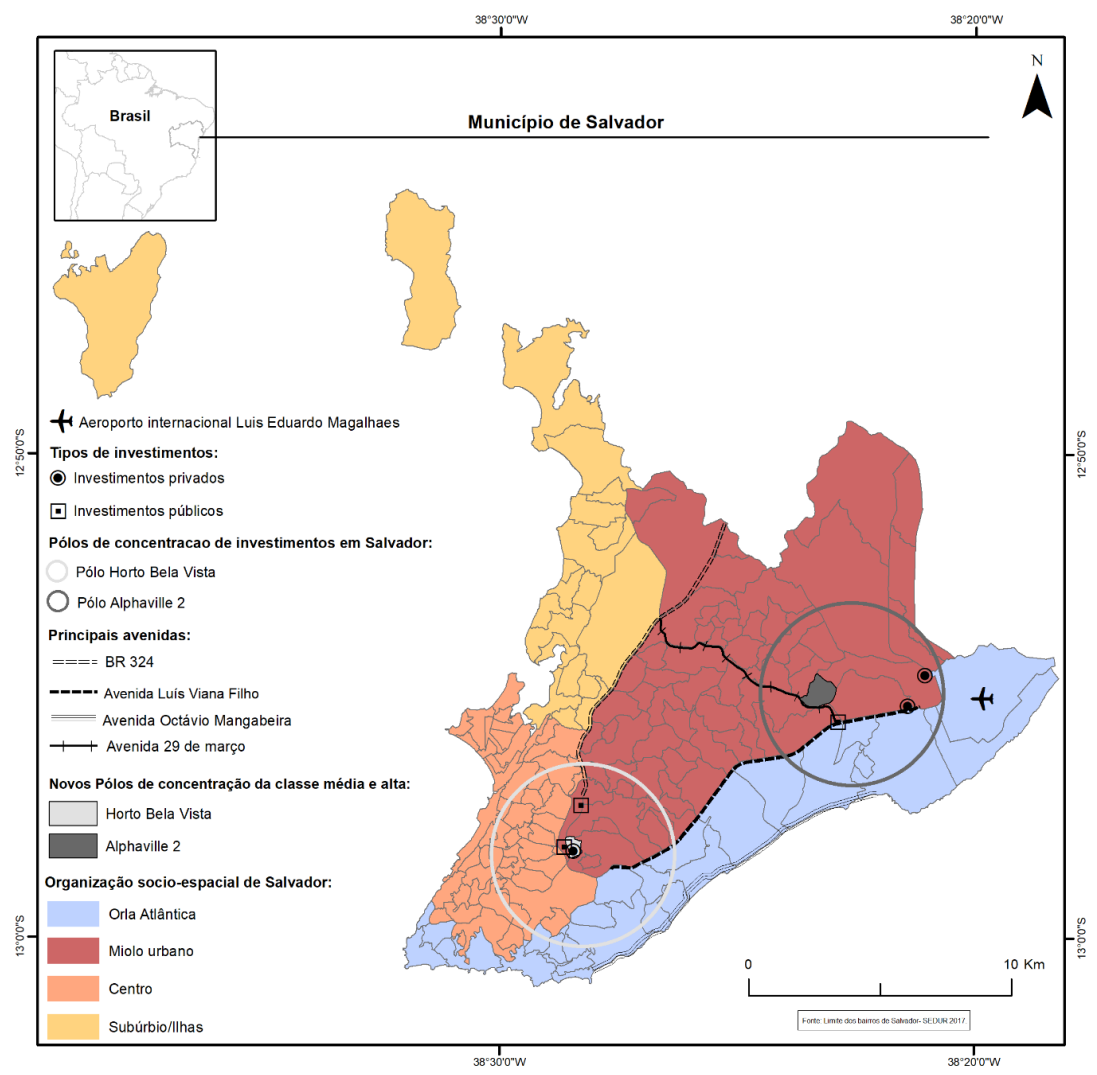

Fonte: Elaboração própria, com base em SEDUR (2017).

Sugere-se a ampliação do número de estudos investigando as articulações multidimensionais entre grupos socialmente distantes nas regiões periféricas das cidades brasileiras à base das considerações de Bourdieu e Husserl para verificar se essa configuração ora reproduz a segregação e segmentação social na escala microurbana, ora promove um maior diálogo entre "centro" e "periferia". Também, faz-se neces- 
sário investigar de forma mais aprofundada os fatores territoriais que condicionam a manutenção - ou mesmo inclusão - de bairros populares nas regiões centrais de Salvador, entre outros, as políticas de Zonas de Especial Interesse Social (ZEIS) e a distribuição de títulos de posse. A integração das ZEIS no Plano Diretor de 2008 de Salvador objetivou implementar instrumentos urbanísticos em prol da população pobre que até então não tinha o direito reconhecido à posse da terra. No caso de Calabar, esse instrumento ajudou a proteger a população contra processos de especulação fundiária.

Convém observar de perto como esse mecanismo pode impedir ao longo prazo a sua expulsão de uma das regiões mais valorizadas da cidade. Evidências empíricas auferidas no caso de Bate Facho sugerem que as políticas de ZEIS não promoveram significantes melhorias para a população local - dada a ausência de investimentos locais na qualidade dos serviços urbanos - nem viabilizaram a regularização da sua situação de moradia através da concessão do título de posse. Ao contrário: a tendência de "elitização" dos espaços intermediários localizados entre o Bate Facho e os condomínios fechados circunferentes, assim como o encarecimento dos serviços urbanos locais, conforme demonstrado no caso do bairro Vila Verde, podem ser considerados como fatores que contribuíram à expulsão dos seus moradores.

(Recebido para publicação em 27 de agosto de 2019)

(Reapresentado em 3 de julho de 2020)

(Aprovado para publicação em 10 de dezembro de 2020)

\section{NOTAS}

1. Uma parte dos resultados auferidos nesta pesquisa, particularmente os achados empíricos dos bairros Calabar e Bate Facho, provém da tese de doutorado do autor deste artigo.

2. Este conceito se define como as desvantagens socioeconômicas que impactam nas condições de vida do indivíduo em decorrência da sua inserção em determinados contextos sociorresidenciais.

3. O termo inner city engloba a todos os bairros localizados na região central das metrópoles estadunidenses que comportam elevadas taxas de pobreza e desemprego, além de sofrer da degradação física do habitat e da perda de investimentos em infraestrutura e serviços urbanos.

4. O termo "socialmente distantes" se reporta neste caso às disparidades observadas entre os grupos sociais vivendo em proximidade espacial a partir dos critérios de renda e nível de escolaridade. 
5. Conforme Sampson (2012), o conceito collective efficacy combina a coesão social e a confiança mútua com a expectativa compartilhada de controle social informal, conceito compreendido como a maneira em que os vizinhos podem contar com o apoio de outrem para manter a ordem pública, monitorar e vigiar as crianças e adolescentes conforme práticas, normas e sanções coletivamente estabelecidas.

6. Os dados estatísticos utilizados na elaboração das Figuras 2 e 3 provêm da Companhia de Desenvolvimento Urbano do Estado da Bahia e se referem ao censo de 2010. Entretanto, o mapeamento da distribuição da taxa de homicídio a partir das Áreas Integradas de Segurança Pública (AISPs), na Figura 4, se baseia nos dados divulgados pela Secretaria de Segurança Pública do Estado da Bahia que se referem aos dados consolidados de 2018.

7. Seguiu-se o índice composto de vulnerabildade social do Atlas Brasil (PNUD, 2020), que, neste estudo, integra as variáveis seguintes (cf. Quadro 1): proporção dos chefes-de família com grau superior de educação, mortalidade infantil por 1.000 crianças nascidas vivas, proporção de vulneráveis à pobreza, proporção de pessoas de 18 anos ou mais sem fundamental completo e em ocupação informal, proporção de crianças de 0 a 5 anos fora da escola, proporção de pessoas de 15 a 24 anos que não estudam, não trabalham e são vulneráveis, na população dessa faixa, proporção de mães chefes de família sem fundamental e com filho menor, no total de mães chefes de família, proporção de crianças extremamente pobres.

8. A critério de "centralidade", na escolha das áreas de estudo, reporta-se neste contexto à distância geográfica dos três bairros analisados do Centro Histórico. Considerando-se as acima delineadas três fases de expansão e a distância geográfica do Centro Histórico, a localização do Calabar pode ser considerada como central. Na década de 1970, antes da construção dos condomínios fechados do Imbuí, o bairro de Bate Facho ainda podia ser classificado como "periférico", em relação ao conjunto da cidade de Salvador. Contudo, em razão da emergência de um segundo centro comercial-financeiro-administrativo na região Iguatemi-Tancredo Neves e da expansão da cidade ao longo da avenida Luís Viana Filho em direção do Aeroporto Internacional de Salvador, o bairro atualmente pode ser classificado como "semiperiférico". Entretanto, a localização do bairro Vila Verde deve ser classificado como "periférico", já que se encontra a mais que 30 quilômetros do Centro Histórico. A escolha dos três bairros analisados se justifica à luz da assunção que a inserção em uma região central, semiperiférica e periférica promove distintas oportunidades de integração socioeconômica das populações pobres.

9. Os dados utilizados no Quadro 1 provêm do Programa das Nações Unidas pelo Desenvolvimento Humano (PNUD) e se referem ao censo de 2010.

10. Os dados utilizados no Quadro 2 provêm das 60 entrevistas conduzidas nos três bairros.

11. Para maiores esclarecimentos sobre as ferramentas metodológicos utilizadas na pesquisa qualitativa, compare o questionário padrão utilizado nas entrevistas, que se encontra no anexo deste artigo. 


\section{REFERÊNCIAS BIBLIOGRÁFICAS}

ALMEIDA, Ronaldo; D'ANDREA, Tiaraju. (2004), “Pobreza e Redes Sociais em uma Favela Paulistana". Novos Estudos CEBRAP, vol. 28, pp. 94-106.

ANDRADE, Luciana T.; SILVEIRA, Leonardo S. (2013), “Efeito-território. Explorações em torno de um Conceito Sociológico". Civitas, vol. 13, n 2, pp. 381-402.

BAYÓN, Maria C.; SARAVÍ, Gonzalo A. (2013), "The Cultural Dimensions of Urban Fragmentation Segregation, Sociability, and Inequality in Mexico City". Latin American Perspectives, vol. 40, $\mathrm{n}^{\circ} 2$, pp. 35-52.

BLANC, Maurice. (2010), "The Impact of Social Mix Policies in France". Housing Studies, vol. $25, \mathrm{n}^{\circ} 2$, pp. $257-272$.

BORSDORF, Axel; BÄHR, Joachim; JANOSCHKA, Michael. (2002), “Die Dynamik stadtstrukturellen Wandels in Lateinamerika im Modell der lateinamerikanischen Stadt". Geographica Helvetica, vol. 57, nº 4, pp. 300-310.

BORSDORF, Axel; HIDALGO, Rodrigo; VIDAL-KOPPMANN, Sonia. (2015), “Social Segregation and Gated Communities in Santiago de Chile and Buenos Aires. A comparison". Habitat International, vol. 15, pp. 1-10.

BOURDIEU, Pierre. (1979), La Distinction. Critique Sociale du Jugement. Paris, Editions de Minuit.

BRIDGE, Garry; BUTLER, Tim; LEES, Lorretta Butler (eds.). (2012), Mixed Communities. Gentrification by stealth? Bristol, Policy Press.

BURAWOY, Michael. (1998), "The Extended Case Method". Sociological Theory, vol. 16, nº 1, pp. 4-33.

BUTLER, Tim; ROBSON, Garry. (2003), London Calling: The Middle Classes and the Remaking of Inner London. Berg, Oxford.

CALDEIRA, Teresa P. do R. (2000), Cidade de Muros. Crime, Segregação e Cidadania em São Paulo. São Paulo, Edusp.

CHAMBOREDON, Jean-Claude; LEMAIRE, Madeleine. (1970), “Proximité Spatiale et Distance Sociale. Les Grands Ensembles et leur Peuplement". Revue Française de Sociologie, vol. $11, \mathrm{n}^{\circ} 1$, pp. 3-33.

CLAMPET-LUNDQUIST, Susan; MASSEY, Douglas S. (2008), “Neighborhood Effects on Economic Self-Sufficiency: A Reconsideration of the Moving to Opportunity Experiment". American Journal of Sociology, vol. 114, nº 1, pp. 107-143.

DAVIDSON, Mark (2010), "Love Thy Neighbour? Social Mixing in London's Gentrification Frontiers". Environment and Planning, vol. 42, n 3, pp. 524-544.

FRIEDRICHS, Jürgen; GALSTER, George, C.; MUSTERD, Sako. (2003), “Neighborhood Effects on Social Opportunities: The European and American Research and Policy Context". Housing Studies, vol. 18, nº, pp. 797-806.

GALSTER, George C. (2007), "Should Policy Makers Strive for a Neighbourhood Social Mix?" Housing Studies, vol. 22, nº 4, pp. 523-545. 
GALSTER, George C.; KILLEN, Sean P. (1995), “The Geography of Metropolitan Opportunity: A Reconnaissance and Conceptual Framework". Housing Policy Debate, vol. 6, nº 1, pp. 7-43.

GLEDHILL, John; HITA, Maria G. (2018), “ Requalificação Urbana e Despejos em Centros Novo e Antigo de Salvador." Cadernos CRH, vol. 31, n 82, pp. 39-58.

HANNERZ, Ulf. (1980), Exploring the City: Inquiries Toward an Urban Anthropology. New York, Columbia University Press.

HÄUßERMANN, Hartmut. (2003), "Armut in der Großstadt. Die Stadtstruktur verstärkt soziale Ungleichheit". Informationen zur Raumentwicklung, vol. 3/4, pp. 143-157.

HUSSERL, Edmund. (1970), Crisis of European Sciences and Transcendental Phenomenology. Chicago, Northwestern University Press.

JANOSCHKA, Michael; BORSDORF, Axel. (2004), “Condomínios Fechados and Barrios Privados: The Rise of Private Residencial Neighbourhoods" in: G. Glasze; C. Webster e K. Frantz (eds.), Private Neighbourhoods. Global and local Perspectives. London, Routledge.

JANOSCHKA, Michael; SEQUERA, Jorge. (2016), "Gentrification in Latin America: Addressing the Politics and Geographies of Displacement". Urban Geography, vol. 37, no 8, pp. 1175-1194.

JOSEPH, Mark; CHASKIN, Robert. (2010), "Living in a Mixed-income Development: Resident Perceptions of the Benefits and Disadvantages of Two Developments in Chicago". Urban Studies, vol. $47, \mathrm{n}^{\circ} 11$, pp. 2347-2366.

KAZTMAN, Ruben (ed.). (1999), Activos y Estructura de Oportunidades: Estudio sobre las Raíces de la Vulnerabilidad Social en Uruguay. Montevideu, Comisión Económica para América Latina y el Caribe.

KAZTMAN, Ruben; RETAMOSO, Alejandro. (2006), Segregación Residencial en Montevideo: Desafíos para la Equidad Educativa. Santiago de Chile, Comisión Económica para América Latina y el Caribe.

KAZTMAN, Ruben; WORMALD, Guillermo (eds.). (2002). Trabajo y Ciudadanía. Los Cambiantes Rostros de la Integración y Exclusión Social en Cuatro Areas Metropolitanas de América Latina. Montevideo, Sofilco.

KEARNS, Ade; MASON, Phil. (2007), "Mixed Tenure Communities and Neighbourhood Quality". Housing Studies, vol. 22, n 5, pp. 661-691.

KLINK, Jeroen; DENALDI, Rosana. (2015), “On Urban Reform, Rights and Planning Challenges in the Brazilian Metropolis". Planning Theory, vol. 15, n 4, pp. 402-417.

KOWARICK, Lúcio. (2009). Viver em Risco. Sobre a Vulnerabilidade Socioeconômica e Civil. São Paulo, Editora 34.

LEES, Loretta; SLATER, Tom; WYLY, Elvin. (2009). Gentrification. New York, Routledge.

LOW, Setha. (2004), Behind the Gated. Life, Security, and the Pursuit of Happiness in Fortress America. New York, Routledge.

LUDWIG, Jens et al. (2008), "What Can We Learn about Neighborhood Effects from the Moving to Opportunity Experiment?" American Journal of Sociology, vol. 114, nº 1, pp. 144-188. 
Stephan Treuke

MARCUSE, Peter; VAN KEMPEN, Ronald. (2000), “Conclusion”. in: P. Marcuse e R. Van Kempen (eds.), Globalizing Cities. A New Spatial Order?, Malden, Blackwell Publishing, pp. 249-275.

MARQUES, Eduardo C. de L. (2010), Redes Sociais, Segregação e Pobreza. São Paulo, Editora Unesp.

MOSER, Caroline. (1998), "The Asset Vulnerability Framwork: Reassessin Urban Poverty Reduction Strategies". World Development, vol. 26, n 1, pp. 1-19.

MUSTERD, Sako et al. (2015), Socio-Economic Segregation in European Capital Cities: Increasing Separation between Poor and Rich. Bonn, Institute for the Study of Labor.

PARNREITER, Christof. (2005), “Tendencias de Desarrollo en las Metrópolis Latinoamericanas en la Era de la Globalización: Los Casos de Ciudad de México y Santiago de Chile". EURE, vol. 31, nº 92, pp. 5-28.

PNUD. (2020). Atlas do Desenvolvimento Humano do Brasil. Disponível em: <http:// www.atlasbrasil.org.br/2013/>. Acesso em: 03 de julho de 2020.

PERLMAN, Janice. (2010), Favela. Four Decades of Living on the Edge in Rio de Janeiro. New York, Oxford University Press.

RIBEIRO, Luis C. de Q. et al. (eds.). (2010), Desigualdades Urbanas, Desigualdades Escolares. Rio de Janeiro, Letra Capital.

ROBERTS, Bryan R.; WILSON, Robert H. (2009), Urban Segregation and Governance in the Americas. New York, Palgrave Macmillan.

RUIZ-TAGLE, Javier. (2016), "La Persistencia de la Segregación y la Desigualdad en Barrios Socialmente Diversos: Un Estudio de Caso en la Florida”. EURE, vol. 42, nº 125, pp. 81-108.

SABATINI, Francisco. (2003), La Segregación Social del Espacio en las Ciudades de America Latina. Washington, D.C., Banco Interamericano de Desarrollo.

SABATINI, Francisco; SALCEDO, Rodrigo. (2007), "Gated Communities and the Poor in Santiago, Chile: Functional and Symbolic Integration in a Context of Aggressive Capitalist Colonization of Lower-Class Areas". Housing Policy Debate, vol. 18, n³ 3, pp. 577-606.

SALCEDO, Rodrigo; TORRES, Alvaro. (2004), "Gated Communities in Santiago: Wall or Frontier?" International Journal of Urban and Regional Research, vol. 28, n 1, pp. 27-44.

SAMPSON, Robert J. (2012), Great American City. Chicago and the Enduring Neighborhood Effect. Chicago: The University of Chicago Press.

SANTORO, Paula F. (2015), “Urban Planning Instruments for Promoting Social Interest Housing: From Zoning to Obligatory Percentages in São Paulo, Brazil, in Dialog with Bogotá, Colombia". Revista Brasileira de Estudos Urbanos e Regionais, vol. 17, n 2, pp. 99-117.

SMALL, Mario L.; FELDMAN, Jessica. (2012), "Ethnographic Evidence, Heterogeneity, and Neighbourhood Effects after Moving to Opportunity", in: M. Van Ham; D. Manley e N. Bailey (eds.), Neighbourhood Effects Research: New Perspectives. Dordrecht, Springer.

SVAMPA, Maristella. (2001), Los que Ganaron: La Vida en los Countries y Barrios Privados. Buenos Aires, Biblos. 
Externalidades Positivas ou Efeitos Excludentes?

WACQUANT, Loic. (2016), Urban Outcasts. A Comparative Sociology of Advanced Marginality. Cambridge, Polity Press.

WILSON, Julius W. (1987), The Truly Disadvantaged: The Inner City, the Underclass and Public Policy. Chicago, The University of Chicago Press. 


\section{ANEXOS}

\section{DIMENSÃO MATERIAL}

Você está atualmente trabalhando no mercado formal/informal? Descreva o acesso ao mercado de trabalho no seu bairro.

Você trabalha no seu próprio bairro ou você tem que se deslocar para outras partes da cidade? Você trabalha atualmente nos condomínios fechados vizinhos/nas áreas residenciais vizinhas da classe média-alta?

Como você avalia o acesso ao sistema de transporte no seu bairro?

Como você avalia o acesso à infraestrutura e ao equipamento urbano no seu bairro e na vizinhança imediata?

Como você avalia a estrutura física do habitat do seu bairro?

Qual e sua avaliação acerca da infraestrutura comercial, social e cultural do bairro?

Quais são as opções de lazer dentro do bairro?

Você compartilha espaços públicos no seu entorno geográfico com os habitantes dos condomínios fechados vizinhos?

Seu bairro se beneficiou de investimentos em infraestrutura local ou em equipamento urbano nos últimos seis meses? Quais são?

\section{DIMENSÃO SOCIAL}

\subsection{Redes Sociais}

\subsubsection{Tipos de Sociabilidade}

\begin{tabular}{l|c|c|c|c|c|c|c}
\hline $\begin{array}{l}\text { Esferas de } \\
\text { sociabilidade }\end{array}$ & $\begin{array}{c}\text { Muita } \\
\text { família e } \\
\text { vizinhança }\end{array}$ & $\begin{array}{c}\text { Muita } \\
\text { vizinhança } \\
\text { e família }\end{array}$ & $\begin{array}{c}\text { Família, } \\
\text { vizinhança } \\
\text { e amigos }\end{array}$ & $\begin{array}{c}\text { Família, } \\
\text { amigos e } \\
\text { lugar de } \\
\text { trabalho }\end{array}$ & $\begin{array}{c}\text { Família, vi- } \\
\text { zinhança e } \\
\text { associaçóes } \\
\text { religiosas }\end{array}$ & $\begin{array}{c}\text { Família, } \\
\text { vizinhança } \\
\text { e estudos }\end{array}$ & $\begin{array}{c}\text { Família, } \\
\text { lugar de } \\
\text { trabalho e } \\
\text { associações } \\
\text { leigas }\end{array}$ \\
\hline Família & & & & & & & \\
\hline Vizinhança & & & & & & & \\
\hline Amigos & & & & & & & \\
\hline Trabalho & & & & & & & \\
\hline Igreja & & & & & & & \\
\hline Associação leiga & & & & & & & \\
\hline Estudos & & & & & & & \\
\hline
\end{tabular}




\subsubsection{Bridging Ties}

Quais são as instituições e organizações localizadas dentro do bairro às quais você se afilia?

Quantas vezes por semana você frequenta estas instituições e organizações: clubes sociais, grupos políticos, grupos de colegas de trabalho, grupos de estudos, clubes de esporte, associações religiosas, sindicatos, associações de moradores?

Quantas vezes por semana você passa sua noite em atividades de lazer com esses cinco tipos diferentes de pessoas: (a) parentes; (b) amigos; (c) vizinhos; (d) colegas de trabalho; (e) amigos não residentes do próprio bairro?

\subsubsection{Bonding Ties}

\subsubsection{Suporte Proporcionado}

\begin{tabular}{l|l|l|l|l|l}
\hline Tipos de suporte & $\begin{array}{c}\text { Cuidado de } \\
\text { criança }\end{array}$ & Vigiar a casa & $\begin{array}{c}\text { Transporte de } \\
\text { mudança }\end{array}$ & $\begin{array}{c}\text { Trabalhos de } \\
\text { construção e } \\
\text { manutenção } \\
\text { da casa }\end{array}$ & $\begin{array}{c}\text { Conselhos } \\
\text { e suporte } \\
\text { emocional }\end{array}$ \\
\hline Parentes & & & & & \\
\hline Amigos & & & & & \\
\hline Vizinhos & & & & & \\
\hline $\begin{array}{l}\text { Colegas de } \\
\text { trabalho }\end{array}$ & & & & & \\
\hline $\begin{array}{l}\text { Amigos não } \\
\text { residentes }\end{array}$ & & & & & \\
\hline
\end{tabular}

2.1.3.2. Suporte Recebido

\begin{tabular}{l|l|l|l|l|l}
\hline Tipos de suporte & $\begin{array}{c}\text { Cuidado de } \\
\text { criança }\end{array}$ & Vigiar a casa & $\begin{array}{c}\text { Transporte de } \\
\text { mudança }\end{array}$ & $\begin{array}{c}\text { Trabalhos de } \\
\text { construção e } \\
\text { manutenção } \\
\text { da casa }\end{array}$ & $\begin{array}{c}\text { Conselhos } \\
\text { e suporte } \\
\text { emocional }\end{array}$ \\
\hline Parentes & & & & & \\
\hline Amigos & & & & & \\
\hline Vizinhos & & & & & \\
\hline $\begin{array}{l}\text { Colegas de } \\
\text { trabalho }\end{array}$ & & & & & \\
\hline $\begin{array}{l}\text { Amigos não } \\
\text { residentes }\end{array}$ & & & & & \\
\hline
\end{tabular}


Stephan Treuke

2.2. Collective Efficacy

\begin{tabular}{ll}
\hline $\begin{array}{l}\text { Dimensão da collective } \\
\text { efficacy }\end{array}$ & Escalas Likert \\
\hline $\begin{array}{l}\text { Índice de expectativas } \\
\text { compartilhadas de controle } \\
\text { social }\end{array}$ & $\begin{array}{l}\text { (1) As crianças ou adolescentes se ausentam na escola e passam o } \\
\text { dia na rua; (2) as crianças e adolescentes desrespeitam ou desobe- } \\
\text { dè sua casa; (4) o posto local de polícia cessará suas atividades de } \\
\text { patrulhamento em vigor de cortes no orçamento. }\end{array}$ \\
\hline Índice de coesão/confiança & $\begin{array}{l}\text { (1) Os moradores aqui se dispõem a ajudar aos seus vizinhos; } \\
\text { nocial }\end{array}$ \\
$\begin{array}{l}\text { nos meus vizinhos; (4) os moradores do bairro não se entendem } \\
\text { muito bem (-1); (5) os moradores deste bairro não compartilham os } \\
\text { mesmos valores e normas sociais (-2). }\end{array}$ \\
\hline $\begin{array}{l}\text { Índice de violência obser- } \\
\text { vada na vizinhança }\end{array}$ & $\begin{array}{l}\text { (1) Briga; (2) uma briga violenta entre vizinhos; (3) briga com arma } \\
\text { acerto de contas entre grupos delinquentes rivais; (7) homicídio. }\end{array}$ \\
\hline $\begin{array}{l}\text { Indice de vitimização } \\
\text { pessoal }\end{array}$ & $\begin{array}{l}\text { Desde que você se mudou para este bairro, alguém cometeu um } \\
\text { crime contra você ou membros da sua família, incluindo: (1) furto; } \\
\text { (2) roubo; (3) assalto; (4) briga; (5) abuso ou violência sexual; (6) } \\
\text { assassinato. }\end{array}$ \\
\hline
\end{tabular}

2.3. Processos de Socialização

\begin{tabular}{ll}
\hline Efeitos de socialização & Questões \\
\hline & $\begin{array}{l}\text { Qual seria, segundo você, a influência dos grupos de pares no } \\
\text { bairro? }\end{array}$ \\
\cline { 2 - 2 } $\begin{array}{l}\text { Grupos de pares e modelos } \\
\text { de referência social na } \\
\text { vizinhança }\end{array}$ & $\begin{array}{l}\text { Existem role models de adultos que possam servir como referência } \\
\text { positiva principalmente para os jovens do bairro? }\end{array}$ \\
\cline { 2 - 2 } & $\begin{array}{l}\text { Existe um contato com modelos de referência da classe média } \\
\text { dentro das relações de vizinhança com os bairros vizinhos? }\end{array}$ \\
\cline { 2 - 2 } & $\begin{array}{l}\text { Caso houver, a partir de quais esferas de sociabilidade estes conta- } \\
\text { tos interclasse se produzem? }\end{array}$ \\
\hline $\begin{array}{l}\text { Grupos de pares e modelos } \\
\text { de referência social na } \\
\text { escola }\end{array}$ & $\begin{array}{l}\text { Você ou seus filhos frequentam uma escola pública no bairro ou } \\
\text { frequentam uma escola pública/privada localizada fora do bairro? }\end{array}$ \\
\cline { 2 - 2 } & $\begin{array}{l}\text { Quais são as perspectivas que as escolas locais promovem para a } \\
\text { mobilidade social e econômica dos adolescentes? }\end{array}$ \\
\cline { 2 - 2 } & $\begin{array}{l}\text { alunos a estudar? } \\
\text { Existem exemplos positivos dentro do seu círculo de amizade em } \\
\text { termos de desempenho escolar e de conclusão do Ensino Médio? }\end{array}$ \\
\cline { 2 - 2 } & $\begin{array}{l}\text { Qual é o papel dos grupos de pares na escola dentro da formação } \\
\text { das crianças e adolescentes? }\end{array}$ \\
\hline
\end{tabular}




\section{Dimensão Simbólica}

1. Qual é a imagem geral do bairro onde você reside veiculada pela mídia televisiva?

2. Em qual medida a reportagem contribui para uma (des)valorização do bairro?

3. A imagem negativa atribuída pela mídia já fez algum parente ou amigo não residente do bairro desistir de visitar você?

4. Qual é a sua impressão geral em relação à proximidade geográfica aos bairros das camadas média e altas?

5. A proximidade aos condomínios contribui para uma valorização ou para uma estigmatização da população do seu bairro?

6. Você sofreu alguma forma de estigmatização devido ao seu lugar de residência?

7. Caso isso se comprovar, quais são as esferas em que você sentiu essa estigmatização (no lugar de trabalho, na procura de um emprego, na contratação de planos de telefone, internet, TV a cabo etc.)?

8. O lugar de residência interfere nas formas de abordagem pelas autoridades públicas, tais como a polícia, os professores da escola etc.?

9. Existem outros canais de comunicação e esferas de sociabilidade que promovem uma maior aproximação social aos residentes dos condomínios?

10. Você se identifica com a sua vizinhança e com a população do bairro de uma forma mais geral (desejo de sair ou de ficar no bairro)?

11. Existem instituições e organizações comunitárias que promovem a construção de uma identidade territorial pautada na coesão e solidariedade?

12. Qual é sua percepção acerca das intervenções urbanas do Estado no bairro, caso existam?

13. Você percebe a inserção do seu bairro em uma região das classes média e alta mais como uma oportunidade ou como um constrangimento? 
Stephan Treuke

\title{
RESUMO
}

Externalidades Positivas ou Efeitos Excludentes? Integração Socioeconômica de Três Bairros Populares em Salvador em relação aos seus Condominios Vizinhos de Elite

A recente transformação espacial das regiões periféricas das cidades latinoamericanas induzida pela construção de condomínios fechados de elite instigou a discussão se este desdobramento favorece a integração socioeconômica das camadas baixas. Visando contribuir a um debate ainda incipiente no Brasil, neste trabalho indaga-se sob quais condições o efeito-território, acometendo as populações dos bairros Calabar, Bate Facho e Vila Verde - Salvador, Brasil - se vê mitigado pela proximidade aos condomínios de elite. À base de entrevistas, identificam-se três mecanismos - as alterações no sistema de suporte, o impacto do crime e a estigmatização da população - que explicam a variabilidade do efeito-território nestes três locais. Discute-se que as oportunidades de participação socioeconômica do indivíduo vis-à-vis seu entorno geográfico estão condicionadas à existência de espaços públicos e ao impacto do crime. O efeito mitigador das externalidades positivas declina nos bairros periféricos Bate Facho e Vila Verde, onde os condomínios fechados fisicamente isolados produzem efeitos excludentes.

Palavras-chave: segregação residencial; pobreza urbana; efeito-território; gentrificação; condomínios fechados

\begin{abstract}
Positive Externalities or Excluding Effects? Socioeconomic Integration of Three Low-Income Neighborhoods in Salvador in Relation to their Elite Neighboring Condominiums

The recent spatial transformation of the peripheral regions of Latin American cities, induced by the construction of elite closed condominiums, prompted the discussion as to whether this development favors the socio-economic integration of the lower classes. In order to contribute to a still incipient debate in Brazil, in this work we ask under what conditions the territory effect that affects the populations of Calabar, Bate Facho, and Vila Verde neighborhoods (from Salvador, Brazil) is mitigated by the proximity to elite condominiums. Based on interviews, three mechanisms that explain the variability of the territory effect in these three locations are identified: changes in the support system, the impact of crime, and the stigmatization of the population. It is argued that the individual's opportunities for socio-economic participation in relation to the geographic environment are conditioned to the existence of public spaces and the impact of crime. The mitigating effect of positive externalities declines in the peripheral neighborhoods Bate Facho and Vila Verde, where physically isolated closed condominiums promote exclusionary effects.
\end{abstract}

Keywords: residential segregation; urban poverty; territory effect; gentrification; closed condominiums 


\section{RÉSUMÉ}

Externalités Positives ou Effets d'Exclusion? Intégration Socio-Économique de Trois Quartiers à Faible Revenu de Salvador, vis-à-vis de Leurs Copropriétés d'élite Voisines

La récente transformation spatiale des régions périphériques des villes latino-américaines, induite par la construction de condominiums fermés d'élite, a suscité une discussion sur la question de savoir si ce développement favorise l'intégration socio-économique des classes populaires. Afin de contribuer à un débat encore naissant au Brésil, dans ce travail, on demande dans quelles conditions l'effet de territoire, affectant les populations des quartiers de Calabar, Bate Facho et Vila Verde-Salvador, Brésil - est atténué par la proximité des condominiums d'élite. À partir d'entretiens, trois mécanismes sont identifiés - l'évolution du système de soutien, l'impact de la criminalité et la stigmatisation de la population - qui expliquent la variabilité de l'effet de territoire dans ces trois lieux. Il est avancé que les occasions de participation socio-économique de l'individu vis-à-vis de son environnement géographique sont conditionnées à l'existence d'espaces publics et à l'impact de la criminalité. L'effet atténuant des externalités positives diminue dans les quartiers périphériques de Bate Facho et Vila Verde, où les condominiums physiquement isolés produisent des effets exclusifs.

Mots-clés: ségrégation résidentielle; pauvreté urbaine; effet territorial; gentrification; copropriété fermée

\section{RESUMEN}

¿Externalidades Positivas o Efectos Excluyentes? Integración Socioeconómica de Tres Barrios Populares en Salvador, frente a Condominios Vecinos de Élite

La reciente transformación espacial de las regiones periféricas de las ciudades latinoamericanas inducida por la construcción de urbanizaciones cerradas de élite instigó la discusión si este despliegue favorece la integración socioeconómica de las capas sociales bajas. Esperando a contribuir a un debate aún incipiente en Brasil, en este trabajo se indaga respecto a las condiciones en las que el efecto territorio, que afecta a las poblaciones de los barrios Calabar, Bate Facho y Vila Verde - Salvador, Brasil -, se ve mitigado por la proximidad a los condominios de élite. A partir de entrevistas, se identifican tres mecanismos - las alteraciones en el sistema de soporte, el impacto del crimen y la estigmatización de la población - que explican la variabilidad del efecto territorio en estos tres territorios. Se discute que las oportunidades de participación socioeconómica del individuo de cara a su entorno geográfico están condicionadas a la existencia de espacios públicos y al impacto del crimen. El efecto mitigador de las externalidades positivas declina en los barrios periféricos Bate Facho y Vila Verde, donde las urbanizaciones cerradas, físicamente aisladas, producen efectos excluyentes.

Palabras clave: segregación residencial; pobreza urbana; efecto territorio; gentrificación; urbanizaciones cerradas. 